\title{
əTropical Precipitation Evolution in a Buoyancy-Budget Framework
}

\author{
Ángel F. Adames, ${ }^{\mathrm{a}, \mathrm{e}}$ Scott W. Powell,${ }^{\mathrm{b}}$ Fiaz Ahmed, ${ }^{\mathrm{c}}$ Víctor C. Mayta, ${ }^{\mathrm{a}, \mathrm{d}}$ ANd J. David Neelin ${ }^{\mathrm{c}}$ \\ ${ }^{a}$ Department of Climate and Space Science and Engineering, University of Michigan, Ann Arbor, Michigan \\ ${ }^{\mathrm{b}}$ Department of Meteorology, Naval Postgraduate School, Monterey, California \\ ${ }^{\mathrm{c}}$ Department of Atmospheric and Oceanic Sciences, University of California, Los Angeles, Los Angeles, California \\ ${ }^{\mathrm{d}}$ Departamento de Ciências Atmosféricas, IAG, Universidade de São Paulo, São Paulo, Brazil
}

(Manuscript received 10 March 2020, in final form 25 September 2020)

\begin{abstract}
Observations have shown that tropical convection is influenced by fluctuations in temperature and moisture in the lower free troposphere (LFT; 600-850 hPa), as well as moist enthalpy (ME) fluctuations beneath the $850 \mathrm{hPa}$ level, referred to as the deep boundary layer (DBL; 850-1000 hPa). A framework is developed that consolidates these three quantities within the context of the buoyancy of an entraining plume. A "plume buoyancy equation" is derived based on a relaxed version of the weak temperature gradient (WTG) approximation. Analysis of this equation using quantities derived from the Dynamics of the Madden-Julian Oscillation (DYNAMO) sounding array data reveals that processes occurring within the DBL and the LFT contribute nearly equally to the evolution of plume buoyancy, indicating that processes that occur in both layers are critical to the evolution of tropical convection. Adiabatic motions play an important role in the evolution of buoyancy both at the daily and longer time scales and are comparable in magnitude to horizontal moisture advection and vertical moist static energy advection by convection. The plume buoyancy equation may explain convective coupling at short time scales in both temperature and moisture fluctuations and can be used to complement the commonly used moist static energy budget, which emphasizes the slower evolution of the convective envelope in tropical motion systems.
\end{abstract}

KEYWORDS: Buoyancy; Deep convection; Entrainment; Precipitation; Thermodynamics

\section{Introduction}

Deep convection plays a key role in the meteorology and climatology of the tropics. It controls the lapse rate of the troposphere and influences the climatological-mean transport of energy (Hartmann 2015). Furthermore, a multitude of tropical phenomena are tightly coupled to deep convection: the intertropical convergence zone, monsoon systems, El Niño-Southern Oscillation (ENSO), the Madden-Julian oscillation (MJO) (Madden and Julian 1972), convectively coupled waves (Kiladis et al. 2009), and tropical cyclones. These phenomena can have major impacts on tropical and extratropical weather and are important sources of predictability (Kim et al. 2018; Tang et al. 2018). While the importance of tropical deep convection cannot be understated, the processes that lead to its onset, evolution and coupling with the large-scale circulation have remained elusive (Kiladis et al. 2009; Kuo et al. 2017; Schiro and Neelin 2019). Furthermore, an accurate representation of convection and its variability in global climate models (GCMs) remains a significant challenge (Taylor et al. 2012; Stanfield et al. 2016).

๑ Denotes content that is immediately available upon publication as open access.

\footnotetext{
${ }^{\mathrm{e}}$ Current affiliation: University of Wisconsin-Madison, Madison, Wisconsin.

Corresponding author: Ángel F. Adames, angel.adamescorraliza@ wisc.edu
}

Scale analysis of the tropical belt (Charney 1963; Yano and Bonazzola 2009) revealed that a simple thermodynamic balance prevails: Diabatic heating is approximately balanced by vertical advection of dry static energy (or similarly potential temperature or dry entropy). Because of the weak Coriolis force, dry gravity waves are very effective at eliminating temperature fluctuations (Bretherton and Smolarkiewicz 1989; Wolding et al. 2016). This adjustment process results in a relatively homogeneous distribution of temperature, where horizontal and temporal fluctuations in free-tropospheric temperatures rarely exceed $1 \mathrm{~K}$ (Sobel and Bretherton 2000). Thus, to leading order, the tropical troposphere is in weak temperature gradient (WTG) balance (Sobel et al. 2001). The application of WTG balance has led to many advances in our understanding of tropical phenomena such as the MJO, the Walker circulation, the diurnal cycle of convection and tropical cyclogenesis (Bretherton and Sobel 2002; Raymond and Sessions 2007; Chikira 2014; Ruppert and Hohenegger 2018).

While WTG balance is the dominant thermodynamic balance in the tropical free troposphere, it is inapplicable in the planetary boundary layer (PBL) (Sobel and Bretherton 2000). In this layer, energy and momentum exchanges with the surface result in strong turbulent mixing, a process that dominates over the gravity wave adjustment process that leads to WTG balance. Instead, observations indicate that in convecting regions, a balance exists between the energy input from surface fluxes and the energy sink that arises from convective downdrafts and turbulent entrainment (Emanuel 1993; Raymond 1995; Thayer-Calder and Randall 2015; de Szoeke 2018). This balance is often referred to as boundary 


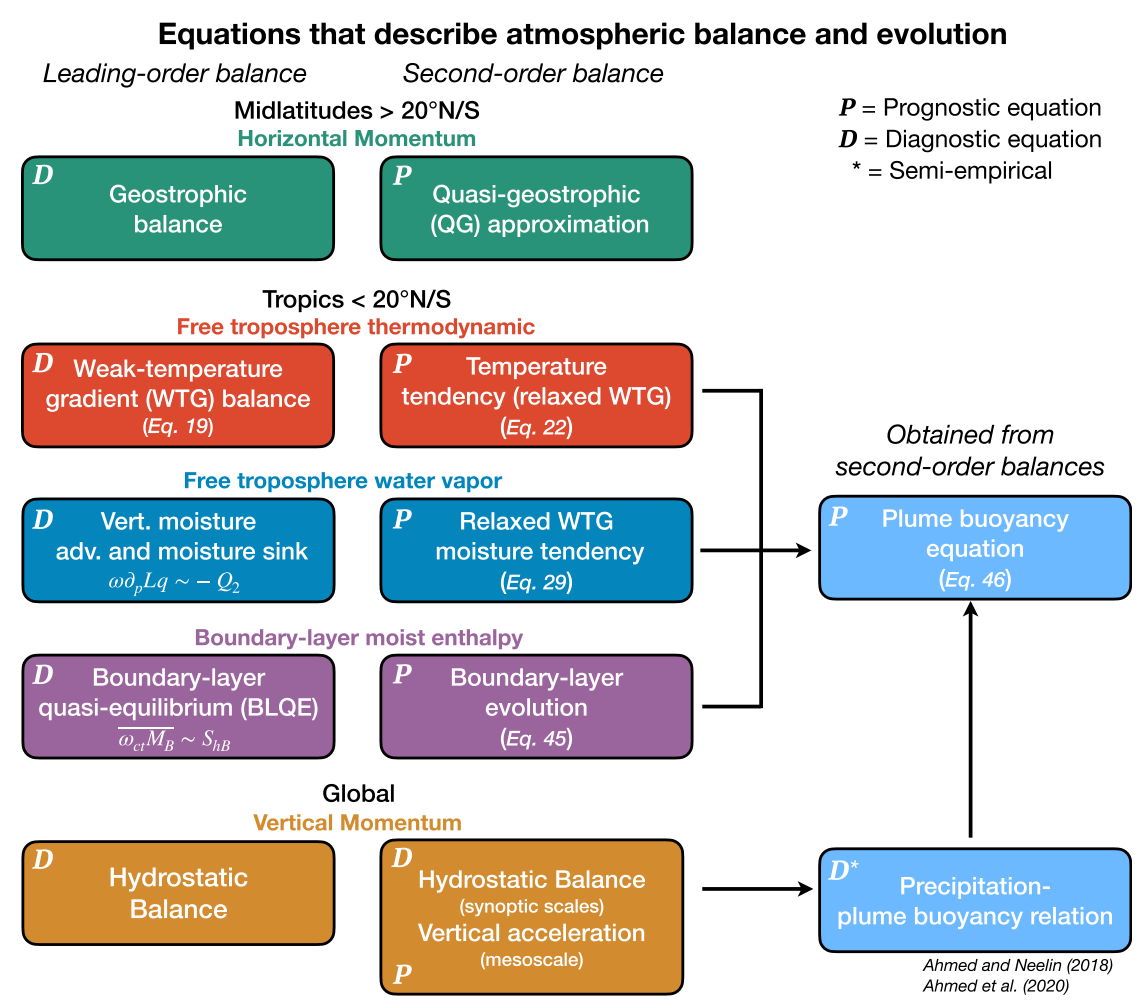

FIG. 1. Flowchart describing some leading-order and second-order balances of the basic equations for atmospheric flow. Arrows depict the second-order balances used to estimate the evolution of buoyancy. $P$ and $D$ in the top left of each box denote prognostic and diagnostic equations, and an asterisk means that a semiempirical relationship is used.

layer quasi equilibrium ${ }^{1}$ (BLQE; Raymond 1997 and references therein), as is often used as a simple convective parameterization (Yano and Emanuel 1991; Emanuel 2019).

While the strict application of WTG and BLQE have provided numerous insights about the nature and occurrence of deep convection, they are still incomplete treatments of the tropical atmosphere. Observations reveal that temperature fluctuations in the lower free troposphere (LFT), although small, modulate the convective available potential energy (CAPE) and convective inhibition (CIN) in ways that can enhance or suppress deep convection (Mapes 2000; Raymond et al. 2006; Kuang 2008). Furthermore, observations suggest that water vapor fluctuations in the LFT play a central role in the organization of deep convection (Raymond 2000; Grabowski and Moncrieff 2004; Sahany et al. 2012). This regulating role is achieved through dry air entrainment and dilution reducing the buoyancy of rising cumulus clouds (Lucas et al. 1994; Hannah 2017; Kuo et al. 2017). To further complicate matters, large fluctuations of PBL moist enthalpy (ME) are observed over daily and synoptic time scales, which modulate CAPE (Donner and Phillips 2003). Indeed, observed variations of

\footnotetext{
${ }^{1}$ Long-term balances of the energetics of the PBL are also part of the convective quasi-equilibrium hypothesis posited by Arakawa and Schubert (1974) and further discussed by Emanuel et al. (1994).
}

moisture and temperature in the LFT as well as fluctuations of PBL ME coincide with a multitude of atmospheric conditions that enhance or suppress rainfall (Powell 2019).

In spite of these challenges, recent efforts to elucidate the relationship between the atmospheric thermodynamic environment and rainfall have yielded promising results. Recently, Ahmed and Neelin (2018, henceforth AN18) developed a framework aimed at understanding precipitation within the context of an entraining plume model. In their framework, plumes rising out of the PBL entrained environmental air through a mass inflow profile akin to that observed in organized convection (Kingsmill and Houze 1999; Mechem et al. 2002; Schiro et al. 2018). They found that the mean buoyancy of the plume in the LFT was highly correlated with precipitation. Thus, their precipitation-buoyancy relation may serve as the foundation for a conceptual model of tropical rainfall that includes the aforementioned key thermodynamic variables.

In Fig. 1, leading-order dynamic balances in the atmosphere (left column) are paired with formulations of second-order balances (right column) in the same-colored boxes that describe the evolution of the quantities listed by same-colored text. For example, in the midlatitudes, the leading-order balance in the horizontal momentum equations (green) is geostrophic balance. The second-order balance describes the evolution of the geostrophic wind as formulated in the quasigeostrophic approximation. Similar balances for the tropics can and have been derived 
in the thermodynamic equations. In this study, the second-order balances for the free-tropospheric thermodynamic and moisture and PBL ME equations are derived from their leading-order balances. These are then used to derive a buoyancy tendency equation based on the precipitation-buoyancy relation of AN18, which itself can be derived from the second-order balance in vertical momentum.

This study is structured as follows. Data and methods are described in section 2. Section 3 discusses the buoyancy of an entraining plume and its relation to tropical rainfall. Section 4 derives the leading and second-order thermodynamic equations used to understand buoyancy evolution. In section 5 we obtain a prognostic equation for plume buoyancy and analyze the processes that lead to its evolution. A concluding discussion is offered in section 6 .

\section{Data and methods}

\section{a. ERA5 and TRMM $3 B 42$}

We utilized output from the fifth reanalysis from the European Centre for Medium-Range Weather Forecasts (ECMWF) (ERA5; Hersbach et al. 2019). We used instantaneous fields with a time interval of $3 \mathrm{~h}$, spanning the 40-yr interval of 1979-2018. The ERA5 data used have horizontal resolution of $0.25^{\circ} \times 0.25^{\circ}$ and 14 vertical levels from 1000 to $600 \mathrm{hPa}$. We make use of the following ERA5 fields: precipitation rate $(P)$, temperature $(T)$, specific humidity $(q)$, and vertical velocity $(\omega)$. Only data within the $15^{\circ} \mathrm{N} / \mathrm{S}$ latitude belt are used.

In section 5 we make use of precipitation data from the 3-hourly, $0.25^{\circ} \times 0.25^{\circ}$ horizontal resolution Tropical Rainfall Measuring Mission (TRMM) 3B42 version 7A (Huffman et al. 2007) dataset. The data are area averaged over the Dynamics of the Madden-Julian Oscillation (DYNAMO) (Yoneyama et al. 2013) northern array domain $\left(0^{\circ}-5^{\circ} \mathrm{N}, 73^{\circ}-80^{\circ} \mathrm{E}\right)$ in order to create a time series of rainfall that can be compared to the in situ sounding-based data.

\section{b. Soundings}

We complemented the reanalysis data by also using sounding data from Majuro $\left(7.1^{\circ} \mathrm{N}, 171.4^{\circ} \mathrm{E}\right)$, Manaus $\left(3.2^{\circ} \mathrm{S}, 59.9^{\circ} \mathrm{W}\right)$, and Gan $\left(0.6^{\circ} \mathrm{S}, 73.1^{\circ} \mathrm{E}\right)$. For the former two, twice-daily observations from a land-based rawinsonde station network for 2000-13 were obtained from the Integrated Global Radiosonde Archive (IGRA; Durre et al. 2006). The rawinsonde dataset was linearly interpolated in pressure to regular $25-\mathrm{hPa}$ intervals. The sounding data are used to obtain the mean values of the mean thermodynamic variables and their variance, which are in turn used in the scale analysis (see Table 3).

Furthermore, evaluation of the plume buoyancy equation in section 5 was performed with the rawinsonde measurements taken from the DYNAMO northern sounding array (NSA), located in the central equatorial Indian Ocean (Ciesielski et al. 2014). Stations in the NSA were Gan Island $\left(0.69^{\circ} \mathrm{N}, 73.51^{\circ} \mathrm{E}\right)$, the $\mathrm{R} / \mathrm{V}$ Revelle $\left(0^{\circ}, 80.5^{\circ} \mathrm{E}\right)$, Colombo $\left(6.91^{\circ} \mathrm{N}, 79.878^{\circ} \mathrm{E}\right)$, and Malé $\left(4.91^{\circ} \mathrm{N}, 73.53^{\circ} \mathrm{E}\right)$. Ciesielski et al. (2014) describes the details of the sounding data, observation characteristics, and quality-control procedures for DYNAMO soundings. A complete description of the thermodynamic budget terms used in section 5 is provided by Johnson et al. (2015).

\section{c. Linear regression}

The relationship between LFT-averaged plume buoyancy $B_{L}$ and terms describing its tendency was determined with DYNAMO soundings using linear regression following the same procedure as many previous studies (e.g., Straub and Kiladis 2002; Sumi and Masunaga 2016; among others). The results presented in section 5 were obtained by linearly regressing 3-hourly plume buoyancy equation terms and TRMM rainfall against the $B_{L}$ anomaly time series. The $B_{L}$ anomalies were calculated for 10 October31 December. The linear regression results were then scaled to a $0.025 \mathrm{~m} \mathrm{~s}^{-2}$ anomaly at zero lag, a typical value that is associated with the occurrence of deep convection. Because of the use of linear regression, the fields that are discussed in section 5 are anomalies that correspond to fluctuations with respect to a $B_{L}$ time series.

\section{Plume buoyancy and tropical precipitation}

We define the buoyancy of an idealized rising plume as

$$
B=g \frac{\theta_{e u}-\theta_{e}^{*}}{\kappa \theta_{e}^{*}},
$$

where $\theta_{e u}$ is the equivalent potential temperature of a rising entraining plume (the subscript $u$ refers to updraft); $\theta_{e}^{*}$ is the saturation equivalent potential temperature of the surrounding environment; and

$$
\kappa=1+\frac{L^{2} q^{*}}{c_{p} R_{v} T^{2}}
$$

is a variable that scales the numerator terms in Eq. (1a) to the difference between plume and environmental temperature (see appendix A), where $q^{*}$ is the saturation specific humidity, $L$ is the latent heat of vaporization, $c_{p}$ is the specific heat of dry air, and $R_{v}$ is the gas constant of water vapor. Their units and values are shown in Table 1, and the main variables and their definitions and units are shown in Table 2.

The measure of plume buoyancy in Eq. (1a) is a variant of the standard potential temperature-based buoyancy [see Eq. (8.1) in Petty 2008]. It is rewritten so that the plume's contribution to $B$ is expressed in terms of $\theta_{e}$, a variable that is approximately conserved during moist adiabatic processes. Equation (1a) defines buoyancy in the same way as AN18, except that it is divided by $\kappa$. The inclusion of $\kappa$ results in buoyancy values that are $\sim 3$ times smaller than those reported in AN18. However, the salient results of both papers are nearly unaffected by this factor. We will use the definition of buoyancy from Eq. (1a) since it can be obtained directly from the traditional temperature-based definition of $B$, as discussed in appendix A.

Following AN18, we can diagnose $\theta_{e u}$ in terms of the environmental $\theta_{e}$ if we know how the environment influences the plume. By assuming the environmental air is incorporated into the plume through dynamic rather than turbulent entrainment (Houghton and Cramer 1951; de Rooy et al. 2013), the relationship between $\theta_{e u}$ and $\theta_{e}$ can be written as

$$
\theta_{e u}(p)=\frac{1}{\omega_{u}(p)} \int_{p_{s}}^{p} \frac{\partial \omega_{u}}{\partial p^{\prime}} \theta_{e}\left(p^{\prime}\right) d p^{\prime},
$$


TABLE 1 . Constants used in this study with their units and values.

\begin{tabular}{clcc}
\hline \hline Quantity & \multicolumn{1}{c}{ Description } & Value & Units \\
\hline$c_{p}$ & Specific heat capacity of dry air & 1004 & $\mathrm{~J} \mathrm{~kg}^{-1} \mathrm{~K}^{-1}$ \\
$R_{d}$ & Gas constant of dry air & 287 & $\mathrm{~J} \mathrm{~kg}^{-1} \mathrm{~K}^{-1}$ \\
$R_{v}$ & Gas constant of water vapor & 461 & $\mathrm{~J} \mathrm{~kg}^{-1} \mathrm{~K}^{-1}$ \\
$L$ & Latent heat of vaporization & 2.5 & $\times 10^{6} \mathrm{~J} \mathrm{~kg}^{-1}$ \\
$g$ & Gravitational acceleration & 9.8 & $\mathrm{~m} \mathrm{~s}^{-2}$ \\
$p_{t}$ & Pressure at the top of the DBL & 850 & $\mathrm{hPa}$ \\
$p_{f}$ & Pressure at the top of the LFT & 600 & $\mathrm{hPa}$ \\
$\Delta_{B}$ & Pressure thickness of the DBL & 150 & $\mathrm{hPa}$ \\
$p_{L}$ & Pressure thickness of the LFT & 250 & $\mathrm{hPa}$ \\
$w_{B}$ & Weighted contribution of the DBL to $B_{L}$ & 0.59 & - \\
$w_{L}$ & Weighted contribution of the LFT to $B_{L}$ & 0.41 & - \\
$\gamma_{q}$ & Sensitivity of buoyancy to $q_{L}$ fluctuations & - \\
$\gamma_{T}$ & Sensitivity of buoyancy to $T_{L}$ fluctuations & 4.3 & - \\
$\tilde{\pi}$ & Ratio of DBL and LFT Exner functions & 0.93 & - \\
\hline
\end{tabular}

where $\omega_{u}$ is the mass flux of the entraining updraft. It is conventional to define the mass flux as $M_{u}=-\sigma \omega_{u}^{*}$, where $\sigma$ is the fraction of the domain that is occupied by updrafts, and $\omega_{u}^{*}$ is the vertical velocity within the updraft (Yanai et al. 1973). However, we define the mass flux as $\omega_{u}=-M_{u}$ so that the notation is consistent with studies that use the WTG approximation to estimate vertical velocities (Raymond and Zeng 2005; Adames 2017).

Recent observations indicate that $\omega_{u}$ can be approximated as a linear function in the lower troposphere for both organized and small-scale convection (Schiro et al. 2018; Schiro and Neelin 2019). Following Schiro and Neelin (2019) and Ahmed et al. (2020, henceforth $\mathrm{AAN})$, we can assume that $\omega_{u} \simeq-a_{c}\left(p_{s}-p\right)$, where $a_{c}$ is a constant. Using this definition of $\omega_{u}$, Eq. (2) simplifies to

$$
\theta_{\text {eu }}(p)=\frac{1}{p_{s}-p} \int_{p}^{p_{s}} \theta_{e}\left(p^{\prime}\right) d p^{\prime},
$$

which indicates that $\theta_{e u}$ is simply the average $\theta_{e}$ of the layer beneath. It is worth pointing out that assuming this type of mass flux profile is equivalent to assuming an entrainment rate that is inversely proportional to height (Siebesma et al. 2007). The effects of assuming slightly different vertical entrainment profiles were found to be modest by Schiro et al. (2018).

Previous studies have shown that water vapor in the LFT as well as fluctuations in CAPE and CIN play an important role in the occurrence and organization of tropical convection (Mapes 2000; Grabowski and Moncrieff 2004; Raymond et al. 2006; Tulich and Mapes 2010; Kuang 2010). Based on results from previous studies, AN18 posited that buoyancy averaged over the LFT $\left(B_{L}\right)$ can robustly diagnose precipitation over the tropics. This measure of plume buoyancy combines the known sensitivity of convection to lower-tropospheric temperature and moisture into a single variable. AAN simplified the framework by showing that $B_{L}$ can be described in terms of the $\theta_{e}$ and $\theta_{e}^{*}$ of the LFT and those of a "deep boundary layer" (DBL), ${ }^{2}$ the layer

\footnotetext{
${ }^{2}$ Over the tropics the top of the PBL is usually beneath $850 \mathrm{hPa}$, hence our definition of DBL. However, the PBL can sometimes be deeper than the DBL defined here, especially over land.
}

of the lower troposphere that lies beneath $850 \mathrm{hPa}$, which usually contains the PBL. A schematic describing $B_{L}$ and the fields involved in its definition is shown in Fig. 2. AAN defined the LFT as the layer that lies between the top of the DBL and a pressure level near where the $0^{\circ} \mathrm{C}$ isotherm is located. The pressure level that corresponds to the top of the DBL, $p_{t}$ is taken to be $850 \mathrm{hPa}$. The top of the LFT $\left(p_{f}\right)$ is taken to be $600 \mathrm{hPa}$. This definition is

TABLE 2. Main variables and definitions used in this study.

\begin{tabular}{|c|c|c|}
\hline Variable & Description & Units \\
\hline LFT & Lower free troposphere & - \\
\hline DBL & Deep boundary layer & - \\
\hline$B$ & Plume buoyancy & $\mathrm{m} \mathrm{s}^{-2}$ \\
\hline$\theta$ & Potential temperature & K \\
\hline$\theta_{e}$ & Equivalent potential temperature & $\mathrm{K}$ \\
\hline$\theta_{e u}$ & $\begin{array}{l}\text { Entraining plume equivalent potential } \\
\text { temperature }\end{array}$ & K \\
\hline$\theta_{e}^{*}$ & $\begin{array}{l}\text { Saturation equivalent potential } \\
\text { temperature }\end{array}$ & $\mathrm{K}$ \\
\hline$T$ & Temperature & $\mathrm{K}$ \\
\hline$q$ & Specific humidity & - \\
\hline$q^{*}$ & Saturation specific humidity & - \\
\hline$h$ & Moist enthalpy (ME) & $\mathrm{J} \mathrm{kg}^{-1}$ \\
\hline$h^{*}$ & Saturation ME & $\mathrm{J} \mathrm{kg}^{-1}$ \\
\hline$s$ & Dry static energy (DSE) & $\mathrm{J} \mathrm{kg}^{-1}$ \\
\hline$m$ & Moist static energy (MSE) & $\mathrm{J} \mathrm{kg}^{-1}$ \\
\hline $\mathbf{v}$ & Horizontal wind vector & $\mathrm{m} \mathrm{s}^{-1}$ \\
\hline$Q_{1}$ & Apparent heating & $\mathrm{J} \mathrm{kg}^{-1} \mathrm{~s}^{-1}$ \\
\hline$Q_{2}$ & Apparent moisture sink & $\mathrm{J} \mathrm{kg}^{-1} \mathrm{~s}^{-1}$ \\
\hline$Q_{c}$ & Convective heating & $\mathrm{J} \mathrm{kg}^{-1} \mathrm{~s}^{-1}$ \\
\hline$Q_{r}$ & Radiative heating & $\mathrm{J} \mathrm{kg}^{-1} \mathrm{~s}^{-1}$ \\
\hline$\omega$ & Vertical pressure velocity & $\mathrm{Pa} \mathrm{s}^{-1}$ \\
\hline$\omega_{Q}$ & Diabatic vertical velocity & $\mathrm{Pa} \mathrm{s}^{-1}$ \\
\hline$\omega_{a}$ & WTG balance departure vertical velocity & $\mathrm{Pas}^{-1}$ \\
\hline$\omega_{c}$ & Convective vertical velocity & $\mathrm{Pa} \mathrm{s}^{-1}$ \\
\hline$\omega_{r}$ & Radiative vertical velocity & $\mathrm{Pas}^{-1}$ \\
\hline$\omega_{u}$ & Updraft mass flux & $\mathrm{Pa} \mathrm{s}^{-1}$ \\
\hline$S_{p}$ & Dry static stability & $\mathrm{J} \mathrm{kg}^{-1} \mathrm{~Pa}^{-1}$ \\
\hline$M_{B}$ & Difference between $m_{B}$ and $m_{t}$ & $\mathrm{~J} \mathrm{~kg}^{-1} \mathrm{~Pa}^{-1}$ \\
\hline$S_{h B}$ & $\begin{array}{l}\text { DBL avg turbulent and radiative } \\
\text { fluxes of } h\end{array}$ & $\mathrm{~J} \mathrm{~kg}^{-1} \mathrm{~s}^{-1}$ \\
\hline
\end{tabular}




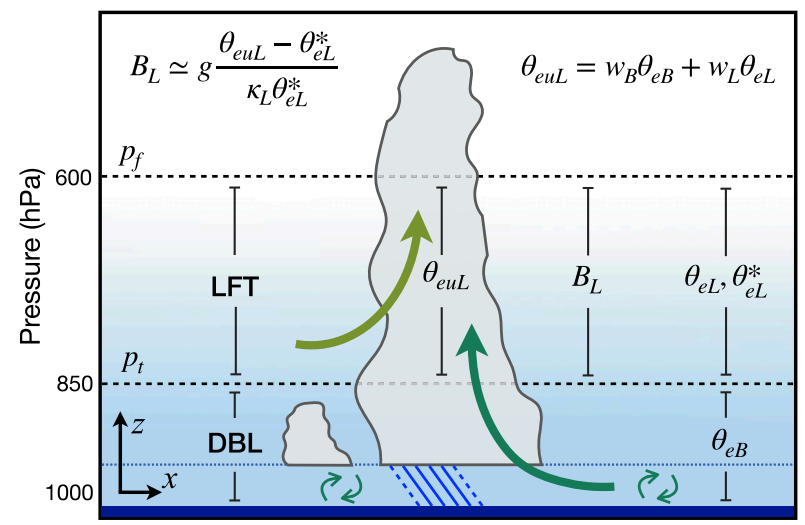

FIG. 2. Schematic describing the entraining plume buoyancy described by AN18 and AAN. By applying a deep inflow profile to prescribe entrainment, the mean LFT plume buoyancy $B_{L}$ can be described by Eq. (4) assuming that $\theta_{e}^{*}$ and $\kappa$ can be replaced by their LFT averages. The two free-tropospheric layers used in AN18 were combined due to the similarities of their weights. The black dashed lines separate the LFT from the midtroposphere and the DBL. The DBL is defined so that its top lies well above of the turbulent subcloud layer (blue dotted line).

different from the one used by AN18 and AAN, who defined it at $500 \mathrm{hPa}$. Observations indicate that the climatological $0^{\circ} \mathrm{C}$ level in the tropics is located near $575 \mathrm{hPa}$ (Johnson et al. 1999). To avoid the complications of latent heat consumption by melting of precipitating ice immediately below the $0^{\circ} \mathrm{C}$ level, we adopt $600 \mathrm{hPa}$ as the top of the LFT.

Based on the aforementioned definitions and simplifications, $B_{L}$ can be expressed as

$$
B_{L} \simeq \frac{g}{\kappa_{L}}(\underbrace{w_{B} \frac{\theta_{e B}-\theta_{e L}^{*}}{\theta_{e L}^{*}}}_{\text {undilute } B_{L}}-\underbrace{w_{L} \frac{\theta_{e L}^{*}-\theta_{e L}}{\theta_{e L}^{*}}}_{\text {saturation deficit }}),
$$

where the subscripts $B$ and $L$ denote averaging over the DBL and over the LFT, respectively (see Fig. 2). The two coefficients in the equation, $w_{B}$ and $w_{L}$ are functions of the relative mass inflow to the plume in the DBL and LFT, respectively, defined following Eqs. (3) and (4) of AAN:

$$
\begin{aligned}
& w_{B}=\frac{\Delta p_{B}}{\Delta p_{L}} \ln \left(1+\frac{\Delta p_{L}}{\Delta p_{B}}\right), \\
& w_{L}=1-w_{B},
\end{aligned}
$$

where we note that the definition of $w_{B}$ has been simplified from that in AAN since we have assumed a constant inflow profile $\omega_{u}$.

The first term in Eq. (4) is a measure of the convective instability of the lower troposphere (Raymond et al. 2015). It is reminiscent of the deep CIN discussed by Raymond et al. It can also be thought as the undiluted component of $B_{L}$. The second term represents the reduction in buoyancy that a rising plume experiences as it entrains and is diluted by free-tropospheric air. In defining Eq. (4), we are assuming that $\theta_{e}^{*}$ and $\kappa_{L}$ exhibit only weak variations in the LFT. While this is true for $\theta_{e}^{*}$, it may not be for $\kappa$, which on average ranges in value from $\sim 2.8$ at $p_{f}$ to $\sim 3.3$ at $p_{t}$ (not shown). While we acknowledge that this is a caveat of this study, we have verified that defining $B_{L}$ following Eq. (4) yields nearly identical results to those obtained if $\kappa$ is not replaced by its layer average. We also note that an integrated buoyancy defined on the entire troposphere behaves similarly (Schiro et al. 2018). We opt for a lower-tropospheric measure of buoyancy, rather than the full-tropospheric average largely due to the simplicity of the equations that arise from using a linear mass flux profile.

We are interested in representing $B_{L}$ in terms of quantities such as temperature and moisture, whose budgets can be readily analyzed. One course of action is to cast Eq. (4) in terms of other quasi-conserved plume variables such as moist static energy (MSE). Alternatively, as in AAN, we can express $c_{p} \theta_{e} \simeq h \Pi^{-1}$ in Eq. (4), where $h=c_{p} T+L q$ is the ME and $\Pi=\left(p / p_{0}\right)^{R_{d} / c_{p}}$ is the Exner function, where $p_{0}=1000 \mathrm{hPa}^{3}$ The resulting expression for $B_{L}$ takes the following form:

$$
B_{L} \simeq w_{B} \frac{g}{\kappa_{L}}\left(\frac{\tilde{\pi} h_{B}-h_{L}^{*}}{h_{L}^{*}}-\gamma_{q} L \frac{q_{L}^{*}-q_{L}}{h_{L}^{*}}\right),
$$

where $\tilde{\pi}=\left(p_{L} / p_{B}\right)^{R_{d} / c_{p}} \simeq 0.93, p_{L}=725 \mathrm{hPa}$ is the mean LFT pressure, $p_{B}=925 \mathrm{hPa}$ is the mean DBL pressure, and

$$
\gamma_{q}=\frac{w_{L}}{w_{B}}
$$

a nondimensional parameter that describes the sensitivity of $B_{L}$ to $q_{L}$.

Figure 3 shows the distribution of rainfall as a function of $B_{L}$. Since $B_{L}$ contains an integrand spanning both positive and negative buoyancy values, it is impacted by fluctuations in both CAPE and CIN. It is clear that rainfall increases rapidly as $B_{L}$ increases from negative values closer to zero. Similar rapid increases for precipitation conditioned on combinations of environmental thermodynamic variables-for example, column saturation fraction, column water vapor or buoyancy-have been modeled as an exponential curve (Bretherton et al. 2004; Rushley et al. 2018) or as a ramp function (AAN; Kuo et al. 2018). While we do not explicitly fit a function to the precipitation curve in Fig. 3, we note a critical value of $B_{L} \sim-0.02 \mathrm{~m} \mathrm{~s}^{-2}$ that would mark the beginning of a linear precipitation regime. The factors that govern this critical buoyancy value are not yet clear. However, any missing physics from the $B_{L}$ formulation when treated as stochastic fluctuations in the value of

\footnotetext{
${ }^{3}$ Using ME instead of MSE is preferable in this study because we are interested $\partial_{t} B_{L}$. In isobaric coordinates, differentiating $B_{L}$ with respect to time yields Eq. (8) when ME is used, while using MSE yields an additional term due to variations in the LFT geopotential. ME is used instead of MSE in order to avoid this additional term. However, an MSE-based definition of $B_{L}$ may be preferred when using height as a vertical coordinate.
} 


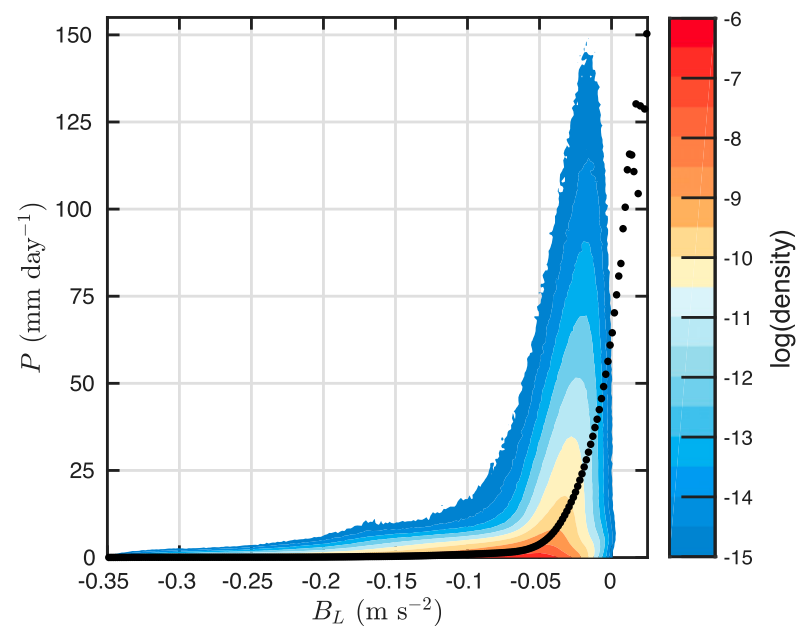

FIG. 3. Normalized distribution of $P$ and $B_{L}$ for ERA5 output over the $15^{\circ} \mathrm{N}-15^{\circ} \mathrm{S}$ latitude belt. Values of $P$ are binned every mm day ${ }^{-1}$ while $B_{L}$ is binned every $0.0015 \mathrm{~m} \mathrm{~s}^{-2}$. The circles show the mean value of the distribution.

critical $B_{L}$ can generate curvature suggestive of an exponential precipitation increase (AAN; Stechmann and Neelin 2011).

While a significant scatter exists in the data points in Fig. 3, the points are more clustered in the $P-B_{L}$ scatterplot than what it is when it is compared to other measures of rainfall such as column water vapor or saturation fraction (not shown) (AAN; Wolding et al. 2020). Further discussion of the joint PDF of precipitation with buoyancy may be found in Kuo et al. (2018), where a cruder estimator of buoyancy (based on column water vapor relative to a temperature-dependent critical value) is used. The robustness of the $P-B_{L}$ in Fig. 3 and the fact that $B_{L}$ accounts for fields that are known to play a key role in the evolution of precipitation such as convective instability and moisture justifies its use as a framework to understand precipitation evolution.

Our interest is both in diagnosing precipitation and understanding the processes that lead to its evolution. To understand precipitation evolution, we differentiate $B_{L}$ with respect to time. Given that $B_{L}$ is a function of $h_{B}, q_{L}$, and $T_{L}$ we can expand the time tendency of $B_{L}$ using the chain rule

$$
\frac{\partial B_{L}}{\partial t}=\frac{\partial B_{L}}{\partial h_{B}} \frac{\partial h_{B}}{\partial t}+\frac{\partial B_{L}}{\partial q_{L}} \frac{\partial q_{L}}{\partial t}+\frac{\partial B_{L}}{\partial T_{L}} \frac{\partial T_{L}}{\partial t},
$$

from which we can obtain the following equation for $B_{L}$ evolution:

$$
\frac{\partial B_{L}}{\partial t}=\frac{w_{B} g}{\kappa_{L} h_{L}^{*}}\left(\tilde{\pi} \frac{\partial h_{B}}{\partial t}+\gamma_{q} L \frac{\partial q_{L}}{\partial t}-\gamma_{T} c_{p} \frac{\partial T_{L}}{\partial t}\right)
$$

where

$$
\gamma_{T} \simeq\left(\frac{\tilde{\pi} h_{B}+\gamma_{q} h_{L}}{h_{L}^{*}}\right)\left(1+\frac{L^{2} q_{L}^{*}}{c_{p} R_{v} T_{L}^{2}}\right)-\gamma_{q}
$$

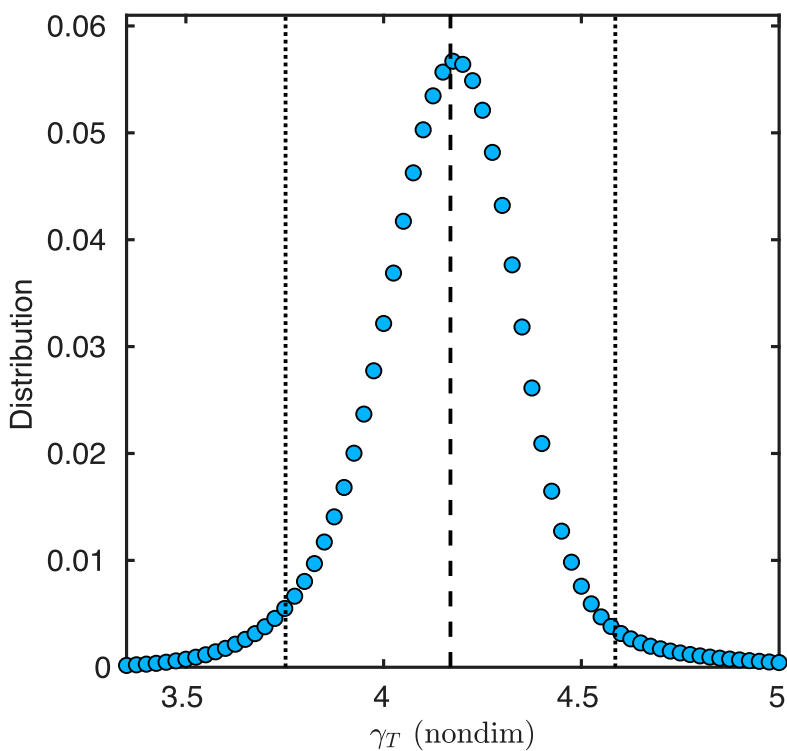

FIG. 4. Normalized distribution of $\gamma_{T}$ [sensitivity of buoyancy to $T_{L}$ from Eq. (10)] over the $15^{\circ} \mathrm{N}-15^{\circ} \mathrm{S}$ latitude belt for ERA5. $\gamma_{T}$ is binned at intervals of 0.025 . The median value of $\gamma=4.2$ is depicted as a vertical dashed line; $95 \%$ of points for ERA5 lie within $10 \%$ of the median value, denoted as the vertical dotted lines.

is a nondimensional parameter that describes the sensitivity of $B_{L}$ to $T_{L}$ fluctuations. In defining $\gamma_{T}$, we have dropped some terms involving $\partial_{T} \kappa_{L}$ since they can be shown to contribute negligibly to the value of $\gamma_{T}$. The distribution of $\gamma_{T}$ over the equatorial belt $\left(15^{\circ} \mathrm{N} / \mathrm{S}\right)$ is shown in Fig. 4. The median value in ERA5 is $\simeq 4$.2. This is the same value that AAN found even though our definition of LFT differs from theirs. Over the equatorial belt of $15^{\circ} \mathrm{N}-15^{\circ} \mathrm{S}, \gamma_{T}$ exhibits only small fluctuations in magnitude. This is due to $\gamma_{T}$ being predominantly determined by $h_{B}$ and $T_{L}$, both which are fairly homogeneous in space and time in the tropics. Because of its small fluctuations, and for the sake of simplicity, we will treat $\gamma_{T}$ as a constant from here on.

It is noteworthy that Eq. (9) exhibits interesting parallels to the way the temperature and moisture equations are combined to create evolution equations for cloud work function or entraining CAPE in certain convective closures (e.g., Arakawa and Schubert 1974; Moorthi and Suarez 1992; Zhang and McFarlane 1995; Neelin et al. 2008).

\section{Large-scale moist thermodynamics under WTG balance}

\section{a. Temperature evolution in the LFT}

Equation (9) indicates that in order to understand the processes that lead to changes in $B_{L}$ we must consider the evolution of $h_{B}$, $T_{L}$, and $q_{L}$. We first consider the thermodynamic (internal energy) equation in isobaric coordinates averaged over a domain that is roughly the area of a GCM grid point $\left(\sim 10^{4} \mathrm{~km}^{2}\right)$ :

$$
c_{p}\left(\frac{\partial \bar{T}}{\partial t}+\overline{\mathbf{v}} \cdot \nabla \bar{T}\right)-\overline{\omega S_{p}}=L(\bar{c}-\bar{e})+\overline{Q_{r}}
$$


where $c_{p}$ is the specific heat at constant pressure, $T$ is the temperature, $\omega$ is the vertical velocity, $\mathbf{v}=u \mathbf{i}+v \mathbf{j}$ is the horizontal vector wind field, $c$ and $e$ are the rate of condensation and evaporation, respectively, $Q_{r}$ is the radiative heating rate, and

$$
S_{p}=-\frac{\partial s}{\partial p}
$$

is the static stability, written so that it is positive, where $s=c_{p} T+$ $\Phi$ is the dry static energy. We are ignoring the contribution of icephase microphysics to heating in Eq. (11) since we are interested in the region of the LFT that lies beneath the $0^{\circ} \mathrm{C}$ level. It is worth pointing out that ice microphysics can significantly influence precipitation (Gao et al. 2006), and the framework discussed in this study does not include these processes.

The overlines in Eq. (11) denote horizontal averaging over the aforementioned domain. In Eq. (11), the horizontal advection of temperature is approximately the product of the large-scale average advection, but the vertical DSE advection term is composed of large-scale vertical advection and the convergence of the vertical flux of DSE by subgrid-scale eddies:

$$
\overline{\omega S_{p}}=\bar{\omega} \bar{S}_{p}-\frac{\partial \overline{\omega^{\prime} S^{\prime}}}{\partial p}
$$

From here on we will drop the overbars except for the eddy flux terms and for large-scale averages that contain eddy covariances in their definition (e.g., $\overline{\omega S_{p}}$ ). For example, Eq. (13) will be written as

$$
\overline{\omega S_{p}}=\omega S_{p}-\frac{\partial \overline{\omega^{\prime} s^{\prime}}}{\partial p}
$$

Following the aforementioned definitions, we can write Eq. (11) as follows:

$$
c_{p} \frac{D_{h} T}{D t}-\omega S_{p}=Q_{1}
$$

where

$$
\frac{D_{h}}{D t}=\frac{\partial}{\partial t}+\mathbf{v} \cdot \nabla_{h}
$$

is the domain-averaged horizontal material derivative, and $Q_{1}$ is the apparent heating rate (Yanai et al. 1973). The apparent heating is composed of contributions from convection $Q_{c}$ and radiative heating $Q_{r}$ :

$$
Q_{1} \equiv Q_{c}+Q_{r},
$$

where $Q_{c}$ includes condensation, evaporation, and vertical eddy heat transport by convective motions:

$$
Q_{c}=L(c-e)-\frac{\partial \overline{\omega^{\prime} s^{\prime}}}{\partial p}
$$

As previously discussed, WTG balance is the leading thermodynamic balance in the tropics. This balance simply states that vertical DSE advection approximately balances diabatic heating:
TABLE 3. Scaling of the equations in section 4 based on estimates

\begin{tabular}{|c|c|}
\hline Equation No. & Scaling \\
\hline (20) & $\underbrace{\omega}_{10^{-1}}=\underbrace{\omega_{Q}}_{10^{-1}}+\underbrace{\omega_{a}}_{10^{-2}}$ \\
\hline (17) & $\underbrace{Q_{1}}_{10^{-1}} \equiv \underbrace{Q_{c}}_{10^{-1}}+\underbrace{Q_{r}}_{10^{-2}}$ \\
\hline (15) & $\underbrace{c_{p} \frac{D_{h} T}{D t}}_{10^{-2}}-\underbrace{\omega S_{p}}_{10^{-1}}=\underbrace{Q_{1}}_{10^{-1}}$ \\
\hline (22) & $\underbrace{c_{p} \frac{D_{h} T}{D t}}_{10^{-2}}-\underbrace{\omega_{a} S_{p}}_{10^{-2}}=0$ \\
\hline (25) & $\underbrace{\frac{D_{h} L q}{D t}}_{10^{-2}}+\underbrace{\omega \frac{\partial L q}{\partial p}}_{10^{-1}}=-\underbrace{Q_{2}}_{10^{-1}}$ \\
\hline \multirow[t]{2}{*}{ (29) } & $\underbrace{\frac{D_{h} L q}{D t}}=-\underbrace{\omega_{a} \frac{\partial L q}{\partial p}}-\underbrace{\omega_{r} \frac{\partial L q}{\partial p}}-\overline{\omega_{c} \frac{\partial m}{\partial p}}$ \\
\hline & $\underbrace{}_{10^{-2}} \underbrace{}_{10^{-2}} \underbrace{\underbrace{}_{10^{-2}}}_{10^{-2}}$ \\
\hline \multirow[t]{2}{*}{ (32) } & $\underbrace{\frac{D_{h} h}{D t}}=-\underbrace{\omega_{a} \frac{\partial m}{\partial p}}-\underbrace{\overline{\omega_{c} \frac{\partial m}{\partial p}}}-\underbrace{\omega_{r} \frac{\partial L q}{\partial p}}$ \\
\hline & $10^{-2} \quad \underbrace{10^{-2}}_{10^{-3}} \quad \underbrace{}_{10^{-2}}$ \\
\hline (36) & $\underbrace{\frac{\partial h_{B}}{\partial t}}_{10^{-2}}=-\underbrace{\{\mathbf{v} \cdot \nabla h\}_{B}}_{10^{-2}}-\underbrace{\overline{\omega_{t} M_{B}}}_{10^{-1}}+\underbrace{S_{h B}}_{10^{-1}}$ \\
\hline
\end{tabular}
of their observed variations. For the scaling, the horizontal winds are assumed to have a scale of $10 \mathrm{~m} \mathrm{~s}^{-1}$, the horizontal scale is assumed to be $10^{6} \mathrm{~m}$, and the variations of $c_{p} T, L q$, and $h$ in the DBL and LFT are rounded from the variances seen in Fig. B1. The first row is in units of $\mathrm{Pas}^{-1}$ while subsequent rows are in units of $\mathrm{J} \mathrm{kg}^{-1} \mathrm{~s}^{-1}$.

$$
-\omega S_{p} \simeq Q_{1}
$$

This implied balance is at least an order of magnitude larger than the temperature tendency over precipitating regions (see Table 3 and Fig. 5). Based on this approximation and following Mapes (1997), we separate the vertical velocity as

$$
\omega=\omega_{Q}+\omega_{a}
$$

so that we can write the leading-order thermodynamic equation as

$$
\omega_{Q} S_{p} \equiv-Q_{1},
$$

where we define $\omega_{Q}$ as a diabatic vertical velocity (Mapes and Houze 1993) that satisfies WTG balance exactly. This definition is analogous to the definition of the geostrophic wind, which is defined in such a way so that it satisfies geostrophic balance exactly. The residual vertical velocity $\omega_{a}$ is the vertical velocity that results from departures from WTG balance.

Based on the decomposition shown in Eq. (21), the residual thermodynamic equation takes the following form:

$$
c_{p} \frac{D_{h} T}{D t}-\omega_{a} S_{p}=0 .
$$



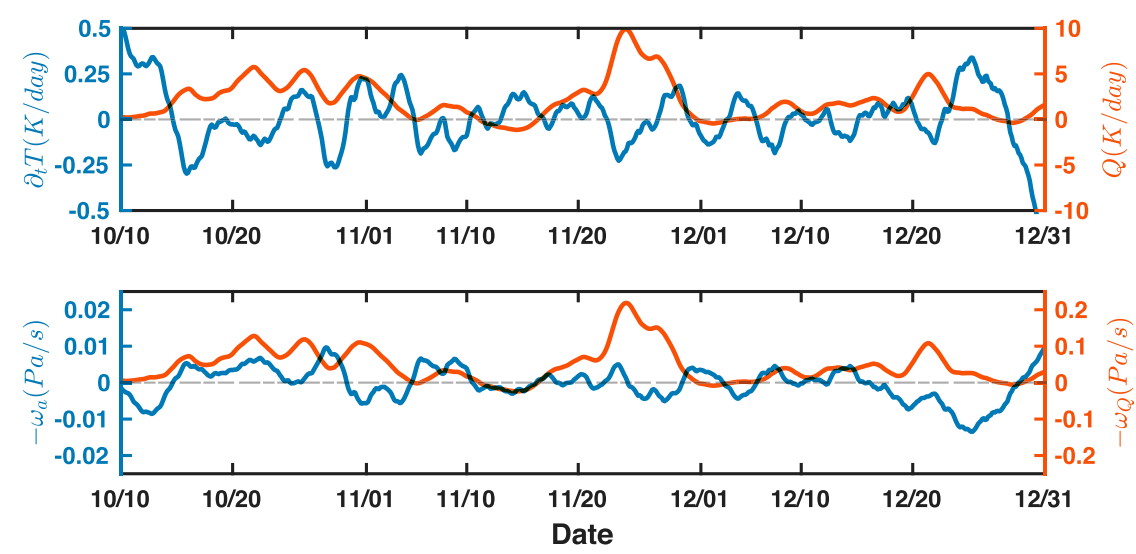

FIG. 5. (top) Time series from the DYNAMO northern array of LFT-averaged temperature tendency (blue, left $y$ axis) and LFT-averaged heating $Q_{1}$ (red, right $y$ axis). (bottom) As in the top panel, but showing LFT-averaged $\omega_{Q}$ calculated using Eq. (21) and $\omega_{a}$ calculated using Eq. (23). In both panels, a 1-day running mean is used to remove diurnal variability from the time series. Note that the scale for $\omega_{a}$ is an order of magnitude smaller than the scale of $\omega_{Q}$.

This equation is a prognostic equation for temperature, whose large-scale free-tropospheric fluctuations are driven by departures from WTG balance driven by adiabatic motions (isentropic ascent, gravity wave activity and Ekman pumping), and transient departures from WTG balance by diabatic heating. When applied strictly (i.e., when $\partial_{t} T$ is not included explicitly), the WTG approximation does not allow gravity waves (Sobel et al. 2001; Bretherton and Sobel 2003). However, Eqs. (21) and (22) together allows for the existence of both free and convectively coupled gravity waves. Following Raymond and Zeng (2005) and Herman and Raymond (2014), we will refer to the use of Eq. (21) alone as "strict WTG" balance and the joint use of Eqs. (21) and (22) as "relaxed" WTG balance.

There are two ways in which $\omega_{a}$ can be estimated. One is through direct estimation of the difference between the total vertical motion and apparent heating, i.e., combining Eqs. (20) and (21):

$$
\omega_{a}=\omega+Q_{1} S_{p}^{-1} .
$$

An alternate way to estimate it is from using Eq. (22), from which $\omega_{a}$ can be obtained if the temperature tendency and the horizontal advection of temperature are known:

$$
\omega_{a}=\frac{c_{p}}{S_{p}} \frac{D_{h} T}{D t} .
$$

An example of the decomposition described above is shown in Fig. 5. Consistent with WTG balance, $\partial_{t} T$ is small as the temperature tendencies are less than $1 \mathrm{~K} \mathrm{day}^{-1}$. LFT-mean heating exhibits significantly more variations, with a minimum value near $-1 \mathrm{~K} \mathrm{day}^{-1}$ and a maximum value near $10 \mathrm{~K} \mathrm{day}^{-1}$. Diabatic heating alone cannot explain the small fluctuations in temperature seen in Fig. 5. If the $T$ fluctuations were driven by $Q_{1}$ their time series would be in quadrature. Instead, fluctuations in $T$ and $Q_{1}$ are sometimes nearly out of phase (e.g., between 1 and 10 November). This result is consistent with the notion that lower temperatures in the LFT are more favorable for convection, as previous studies have posited (Mapes 2000;
Mapes et al. 2006; Raymond et al. 2006) and as indicated by Eq. (6). Estimates of $\omega_{Q}$ and $\omega_{a}$ (with signs reversed) are shown in the bottom panel of Fig. 5. Consistent with the derivation above, $\omega_{a}$ is roughly an order of magnitude smaller than $\omega_{Q}$.

\section{b. Moisture evolution in the LFT}

We can use the first- and second-order thermodynamic equations to obtain a description of the evolution of moisture that includes both diabatic and adiabatic processes. The moisture conservation equation can be written as

$$
\frac{D_{h} q}{D t}+\omega \frac{\partial q}{\partial p}=-\frac{Q_{2}}{L},
$$

where

$$
Q_{2} \equiv L(c-e)+L \frac{\partial \overline{\omega^{\prime} q^{\prime}}}{\partial p}
$$

is the apparent moisture sink (Yanai et al. 1973), which we can rewrite as

$$
Q_{2}=Q_{c}+\frac{\partial \overline{\omega^{\prime} m^{\prime}}}{\partial p}
$$

where the second term on the right-hand side is the vertical eddy flux convergence of MSE, defined as $m=s+L q$.

We can separate $\omega_{Q}$ in terms of vertical velocities that are associated with convective and radiative heating following Eq. (17):

$$
\begin{gathered}
\omega_{Q} \equiv \omega_{c}+\omega_{r}, \\
\omega_{c}=-S_{p}^{-1} Q_{c}, \\
\omega_{r}=-S_{p}^{-1} Q_{r},
\end{gathered}
$$

where $\omega_{c}$ and $\omega_{r}$ are the convective and radiative vertical velocities, respectively. With these definitions the moisture equation takes the following form: 


$$
\frac{D_{h} L q}{D t}=-\left(\omega_{a}+\omega_{r}\right) \frac{\partial L q}{\partial p}-\overline{\omega_{c} \frac{\partial m}{\partial p}},
$$

where

$$
\overline{\omega_{c} \frac{\partial m}{\partial p}}=\omega_{c} \frac{\partial m}{\partial p}+\frac{\partial \overline{\omega^{\prime} m^{\prime}}}{\partial p}
$$

is the total vertical MSE advection by convective motions. We include $\overline{\omega^{\prime} m^{\prime}}$ in this definition since, to a good approximation, subgrid-scale eddies in the LFT are the result of convective motions.

It is worth noting that Eq. (29) can be thought of as a secondorder balance equation since the leading-order balance in precipitating regions is between large-scale vertical moisture advection and $Q_{2}$ (see Fig. 1). It is similar to the moisture budgets described by Chikira (2014), Wolding and Maloney (2015) and Wolding et al. (2016), except that diabatic heating is expressed in terms of vertical velocities, and the contribution from $\omega_{a}$ is included in the equation.

From inspection of Eq. (29) we can see that $\omega_{a}$ and $\omega_{r}$ moisten the atmosphere through vertical moisture advection. Convective processes, however, moisten the atmosphere through vertical MSE advection. While ascent driven by adiabatic processes and radiation usually moistens the troposphere, ascent driven by convection only moistens the atmosphere beneath the minimum in MSE, where the vertical MSE gradient is usually positive (beneath the $650 \mathrm{hPa}$ layer in Fig. B1 in appendix B). Above this level, vertical MSE advection by convection usually dries the troposphere.

Equation (29) also reveals the potential importance of adiabatic motions in moistening the LFT. Because the vertical MSE gradient tends to be substantially smaller than the vertical moisture gradient in this layer, it follows that moistening from convective motions is of similar magnitude to the vertical moisture advection from radiative and adiabatic ascent, as indicated by the scaling shown in Table 3. Alternatively, we can show that these three terms are comparable by noting that the total vertical MSE advection by convection is the difference between the vertical moisture advection from convection and the convective heating rate:

$$
-\overline{\omega_{c} \frac{\partial m}{\partial p}}=-\overline{\omega_{c} \frac{\partial L q}{\partial p}}-Q_{c} .
$$

Thus, given that $-\overline{\omega_{c} \partial_{p} m}$ is the residual of two leading-order terms (see Fig. 1), it can be surmised that it is of the same order of magnitude as the other terms in Eq. (29), as the scale analysis suggests.

\section{c. $M E$ in the free troposphere}

The relaxed WTG thermodynamic [Eq. (22)] and moisture [Eq. (29)] equations may be added to obtain an equation for $\mathrm{ME}$, which is written as follows:

$$
\frac{D_{h} h}{D t}=-\omega_{a} \frac{\partial m}{\partial p}-\omega_{r} \frac{\partial L q}{\partial p}-\overline{\omega_{c} \frac{\partial m}{\partial p}} .
$$

Note that this equation may also be treated as a MSE equation since local fluctuations in ME are approximately those of MSE.
Because of WTG balance, the impact of $\omega_{c}$ on $h$ is the same as $q$ [Eq. (29)]. The $\omega_{a}$ contribution acts on the MSE gradient since it is associated both with temperature and moisture tendencies [Eqs. (22) and (29)]. Radiative heating, under WTG balance, is only implicated with vertical moisture advection.

Equation (32) has several advantages over the traditional MSE budget. First, the contribution of radiative heating to the MSE tendency is included in a single term. In traditional MSE budgets, there is an implicit contribution of radiative heating to vertical MSE advection since $\omega=\omega_{c}+\omega_{r}+\omega_{a}$. Additionally, it is clear that the contribution of $\omega_{a}$ to the evolution of ME is negligible (see Table 3).

It is worth pointing out that if WTG balance is applied strictly, $\partial_{t} T$ and $\omega_{a}$ are dropped from Eq. (32), and both Eqs. (32) and (29) become the WTG-based moisture equation used by Chikira (2014), Wolding et al. (2016) and others.

\section{d. Moisture and thermodynamic equations averaged over the LFT}

We are particularly interested in fluctuations in temperature and moisture averaged over the LFT because of their impact on $B_{L}$, as indicated by Eq. (9). The LFT-averaged thermodynamic and moisture equations can be written as

$$
\begin{aligned}
c_{p} \frac{\partial T_{L}}{\partial t} & =-c_{p}\{\mathbf{v} \cdot \nabla T\}_{L}+\left\{\omega_{a} S_{p}\right\}_{L}, \\
\frac{\partial L q_{L}}{\partial t} & =-\{\mathbf{v} \cdot \nabla L q\}_{L}-\left\{\left(\omega_{a}+\omega_{r}\right) \frac{\partial L q}{\partial p}\right\}_{L}-\left\{\overline{\left.\omega_{c} \frac{\partial m}{\partial p}\right\}_{L},}\right.
\end{aligned}
$$

where $\{\cdot\}_{L}$ denotes averaging over the LFT, e.g.,

$$
\{\mathbf{v} \cdot \nabla q\}_{L}=\frac{1}{p_{t}-p_{f}} \int_{p_{f}}^{p_{t}}(\mathbf{v} \cdot \nabla q) d p .
$$

\section{e. ME averaged over the $D B L$}

As discussed in section 1, WTG is not applicable within the DBL due to the importance of turbulent mixing. However, our definition of the DBL is sufficiently deep so that its top $p_{t}$ lies within the lower free troposphere, where WTG balance is applicable. Thus, we will rewrite the DBL ME equation so that $\omega$ is defined only at $p_{t}$. The DBL-averaged ME equation can be written as

$$
\frac{\partial h_{B}}{\partial t}=-\{\mathbf{v} \cdot \nabla h\}_{B}-\left\{\omega \frac{\partial m}{\partial p}\right\}_{B}+Q_{r B}-\left\{\frac{\partial \overline{\omega^{\prime} m^{\prime}}}{\partial p}\right\}_{B},
$$

where $\{\cdot\}_{B}$ denotes averaging over the DBL. We will express the vertical MSE advection term in terms of the difference between the vertical flux divergence of MSE and MSE convergence:

$$
\omega \frac{\partial m}{\partial p}=\frac{\partial \omega m}{\partial p}-m \frac{\partial \omega}{\partial p}
$$

Assuming that $\omega\left(p_{s}\right) \simeq 0$, and that $\omega$ increases approximately linearly from the surface to the top of the DBL, it can be shown 
that the vertical MSE advection averaged over the DBL can be expressed as

$$
-\left\{\omega \frac{\partial m}{\partial p}\right\}_{B} \simeq-\omega_{t} M_{B}
$$

where

$$
M_{B}=\left(m_{B}-m_{t}\right) / \Delta p_{B}
$$

can be thought as a vertical MSE gradient, where $m_{B}$ is the BL-averaged MSE, $m_{t}$ is MSE at $p_{t}, \omega_{t}$ is the vertical velocity at $p_{t}$, and $\Delta p_{B}$ is the pressure depth of the DBL. Because $p_{t}$ lies in the LFT, we can apply WTG balance to decompose $\omega_{t}$ into its contributions from convection, radiation, and adiabatic motions: $\omega_{t}=\omega_{c t}+\omega_{r t}+\omega_{a t}$.

It is also worth noting that the BL-averaged eddy flux convergence of MSE is composed of the layer-weighted eddy fluxes of MSE at $p_{s}$ and $p_{t}$ :

$$
-\left\{\frac{\partial \overline{\omega^{\prime} m^{\prime}}}{\partial p}\right\}_{B}=\frac{\left(\overline{\omega^{\prime} m^{\prime}}\right)_{t}-\left(\overline{\omega^{\prime} m^{\prime}}\right)_{s}}{\Delta p_{B}}=Q_{c B}-Q_{2 B} .
$$

The term $\left(\overline{\omega^{\prime} m^{\prime}}\right)_{s}$ is the sum of the surface sensible $(H)$ and latent heat (LE) fluxes,

$$
-\frac{\left(\overline{\omega^{\prime} m^{\prime}}\right)_{s}}{\Delta p_{B}}=\frac{g}{\Delta p_{B}}(\mathrm{LE}+H),
$$

while the term $\left(\overline{\omega^{\prime} m^{\prime}}\right)_{t}$ corresponds to the eddy flux of MSE by convective motions, including turbulent cloud detrainment and convective downdrafts. Since most observational and model datasets include the contribution from eddy fluxes, we may be able to estimate $\left(\overline{\omega^{\prime} m^{\prime}}\right)_{t}$ as

$$
\frac{\left(\overline{\omega^{\prime} m^{\prime}}\right)_{t}}{\Delta p_{B}}=Q_{c B}-Q_{2 B}-\frac{g}{\Delta p_{B}}(\mathrm{LE}+H) .
$$

It is worth noting that, by construction, these fluxes partly cancel the surface fluxes. The deviation from this cancellation is determined by the magnitude of $Q_{c B}-Q_{2 B}$, quantities that are available in the DYNAMO sounding data and can be estimated in model and reanalysis data following Yanai et al. (1973) and Johnson et al. (2016).

Because Eq. (40) is composed by a surface turbulent flux term and a convective flux term, it may be more appropriate to consider these contributions separately. The surface fluxes and $Q_{r B}$ can be considered to be sources of DBL ME:

$$
S_{h B}=\frac{g}{\Delta p_{B}}(\mathrm{LE}+H)+Q_{r B} .
$$

The large-scale vertical MSE advection by convection $\left(-\omega_{c} M_{B}\right)$ is summed to the convective eddy flux of MSE at $p_{t}$ to define the total vertical MSE advection by convective motions:

$$
-\overline{\omega_{c t} M_{B}}=-\omega_{c t} M_{B}+\frac{\left(\overline{\omega^{\prime} m^{\prime}}\right)_{t}}{\Delta p_{B}} .
$$

With the aforementioned approximations and definitions, we can write the DBL ME equation as follows:

$$
\frac{\partial h_{B}}{\partial t}=-\{\mathbf{v} \cdot \nabla h\}_{B}-\left(\omega_{a t}+\omega_{r t}\right) M_{B}-\overline{\omega_{c t} M_{B}}+S_{h B} .
$$

Scale analysis of Eq. (45) (Table 3) in convecting regions reveals that the last two right-hand-side terms are dominant. These terms constitute a form of BLQE related to balances discussed by Raymond (1995) and Emanuel (1995). Because these two terms tend to cancel, we could make some simplifications as those done with the application of WTG balance. However, because convection also affects and is affected by $q_{L}$, this balance does not alone control convection. It follows that it may be more useful to understand how DBL ME fluxes and convection affect the evolution of $B_{L}$ and to define the leading balance based on $B_{L}$ instead. The results of this study are generally unaffected if Eq. (36) is used instead of Eq. (45).

\section{The plume buoyancy equation}

Replacing the time tendencies on the right-hand side of Eq. (9) with Eqs. (33), (34) and (45), we obtain what we will refer to as the plume buoyancy equation:

$$
\begin{aligned}
& \frac{\partial B_{L}}{\partial t} \simeq \frac{w_{B} g}{\kappa_{L} h_{L}^{*}}[\underbrace{-\left\{\mathbf{v} \cdot \nabla\left(\gamma_{q} L q-\gamma_{T} c_{p} T\right)\right\}_{L}}_{A} \underbrace{-\tilde{\pi}\{\mathbf{v} \cdot \nabla h\}_{B}}_{B} \\
& \underbrace{-\left\{\omega_{a}\left(\gamma_{q} \partial_{p} L q+\gamma_{T} S_{p}\right)\right\}_{L}}_{C} \underbrace{-\gamma_{q}\left\{\omega_{r} \partial_{p} L q\right\}}_{D} L \underbrace{-\gamma_{q}\left\{\overline{\omega_{c} \partial_{p} m}\right\}_{L}}_{E} \\
& \underbrace{-\tilde{\pi}\left(\omega_{a t}+\omega_{r t}\right) M_{B}}_{F, G} \underbrace{-\tilde{\pi} \overline{\omega_{c t} M_{B}}}_{H}+\underbrace{\tilde{\pi} S_{h B}}_{I}] \text {, }
\end{aligned}
$$

where the right-hand-side terms correspond to

$A$ : horizontal advection of moisture and temperature in the LFT,

$B$ : horizontal advection of $\mathrm{ME}$ in the $\mathrm{BL}$,

$C$ : moistening and cooling by adiabatic vertical motions in the LFT,

$D$ : vertical moisture advection driven by radiative heating in the LFT,

$E$ : vertical MSE advection by convection in the LFT,

$F$ : vertical advection of MSE at the top of the DBL by adiabatic motions,

$G$ : as in $F$, but for radiatively driven vertical motions,

$H$ : as in $F$, but for convection at the top of the DBL,

I: sources of ME in the DBL.

\section{a. Scaling and interpretation}

Scale analysis based on typical synoptic-scale systems (horizontal scale $\sim 1000 \mathrm{~km}$ ), following Table 3 , reveals the following scaling of terms: 


$$
\underbrace{\frac{\partial B_{L}}{\partial t}}_{10^{-7}} \simeq \underbrace{\frac{w_{B} g}{\kappa_{L} h_{L}^{*}}}_{10^{-5}}[\underbrace{A}_{10^{-2}}+\underbrace{B}_{10^{-2}}+\underbrace{C}_{10^{-2}}+\underbrace{D}_{10^{-2}}+\underbrace{E}_{10^{-2}}+\underbrace{F}_{3 \times 10^{-3}}+\underbrace{G}_{3 \times 10^{-3}}+\underbrace{H}_{10^{-1}}+\underbrace{I}_{10^{-1}}] .
$$

Note that the time tendency in $B_{L}$ is $10^{-2} \mathrm{~m} \mathrm{~s}^{-2}$ day ${ }^{-1}$. The scaling reveals once again that the terms that compose BLQE are the leading-order terms. Because term $E$ and $H$ are both related to convective processes, they can be combined with term $I$ to define what we will refer to as the DBL ME source surplus:

$$
S_{h B}^{+}=S_{h B}-\overline{\omega_{c t} M_{B}}-\gamma_{q} \tilde{\pi}^{-1}\left\{\overline{\omega_{c} \partial_{p} m}\right\}_{L},
$$

which can be thought of as the DBL sources of ME that exceed those necessary to maintain existing convection. While the sum of the first two terms constitute the departures of BLQE (Fig. 1), the addition of the third term extends the notion of quasi equilibrium to the LFT. Thus, $S_{h B}^{+}$ can be thought of a departure from so-called "lower troposphere quasi equilibrium" (LQE) (Kuang 2008; Khouider and Majda 2008; Raymond and Herman 2011; Raymond et al. 2015).

Prior to analyzing the evolution of Eq. (46), it is worth interpreting the processes that can lead to the evolution of $B_{L}$ in tropical motion systems and how this evolution can lead to convective coupling. A schematic describing some of these processes is shown in Fig. 6. Convection is modulated differently depending on the layer in which the process occurs even though their impact on $B_{L}$ is qualitatively similar. For example, horizontal moisture advection in the LFT (Fig. 6a) reduces the saturation deficit in Eq. (4). Such a reduction implies that ascending plumes dilute less as they ascend through the troposphere. In the case of horizontal moisture advection in the DBL (Fig. 6b), moistening causes ascending updrafts to be more humid and hence have a larger $\theta_{e}$. As a result, a plume is able to liberate more latent heat from condensation, implying a larger undilute $B_{L}$. Changes in surface heat fluxes have the same impact (Fig. 6c). Cloud-radiative heating, which impacts both the DBL and the LFT may increase undilute $B_{L}$ and reduce the saturation deficit (Fig. 6d).

In synoptic-scale tropical motion systems, departures from WTG balance can arise from large-scale adiabatic lifting. When such processes occur Eq. (46) may be preferable to ME or MSE budgets. As discussed in section $4 \mathrm{c}$ and shown in Table 3, adiabatic motions contribute little to the evolution of ME but are of leading-order importance for the evolution of $B_{L}$ because $\gamma_{q} \partial_{p} L q+\gamma_{T} S_{p} \gg \partial_{p} m$ (note that $\partial_{p} m=\partial_{p} L q-S_{p}$ ). One example of adiabatic motions is steady isentropic lifting (Fig. 6e). In this case we have a cancellation between horizontal temperature advection and adiabatic DSE advection $-c_{p}\{\mathbf{v} \cdot \nabla T\}_{L}=-\omega_{a L} S_{p}$, so that the $B_{L}$ tendency is purely due to vertical moisture advection from isentropic lifting. As a result, isentropic lifting destabilizes the atmosphere through moistening of the troposphere from adiabatic lifting. Scaling of the horizontal temperature advection term indicates that a temperature gradient on the order of $1 \mathrm{~K}(1000 \mathrm{~km})^{-1}$ is sufficient for isentropic lifting to be of leading-order importance. Climatological gradients of this magnitude are observed over the South Asian and African monsoons (Kiladis et al. 2006; Adames and Ming 2018; Russell et al. 2020).

Another example of adiabatic motions arises from gravity waves (Fig. 6f). In this case, adiabatic lifting cools the LFT, increasing undilute $B_{L}$. It also moistens the lower troposphere as moist DBL air is advected upward [term $C$ in Eq. (46)]. By comparing the magnitude of the two contributions (Table 1 and Fig. B1), it can be shown that the cooling contribution is $\sim 3.5$ times larger, so that it contributes to $\sim 78 \%$ of the increase in $B_{L}$. While the vertical advection of DSE and $L q$ are of comparable magnitude, $B_{L}$ is more sensitive to changes in $T_{L}$ than $q_{L}\left(\gamma_{T}>\gamma_{q}\right)$, so that adiabatic cooling has a larger impact on $B_{L}$ than adiabatic moistening. Adiabatic cooling not only increases undilute $B_{L}$, but also reduces the saturation deficit by reducing the saturation specific humidity of the LFT.

\section{b. The plume buoyancy equation in DYNAMO soundings}

Moisture and MSE budgets constructed from tropical field campaign data have yielded valuable insights related to the coupling between convection and the large-scale environment (Sobel et al. 2014; Inoue and Back 2015; Hannah et al. 2016). However, $B_{L}$ is more closely related to the occurrence of deep convection, and a $B_{L}$ budget is therefore expected to offer insights not available from traditional moisture or MSE budgets. Observations or other datasets that provide quantities such as collocated surface fluxes, diabatic heating rates, $Q_{1}$, and $Q_{2}$, as well as state variables, can be leveraged to evaluate $B_{L}$ budgets via Eq. (46), and one example is shown below as a preliminary analysis of the $B_{L}$ budget using DYNAMO sounding data.

Figure 7 shows a time series of $B_{L}$, TRMM 3 B 42 rainfall and the different terms in Eq. (46) obtained from a lag regression onto a $B_{L}$ time series calculated from DYNAMO sounding data (section 2c). A clear peak in $B_{L}$ is shown at lag 0 , and TRMM $3 B 42$ precipitation increases at this point. The maximum rainfall lags the $B_{L}$ maximum by $6 \mathrm{~h}$. The time lag between $B_{L}$ and precipitation can likely be largely attributed to the widespread occurrence of stratiform precipitation that occurs concurrently with convection while $B_{L}$ is reduced. Indeed, Zuluaga and Houze (2013) showed that about 1/3 of the precipitation echo seen by radar at the time of peak precipitation during DYNAMO (at 2-day time scales) was broad stratiform. TRMM 3B42 may overestimate rainfall in such scenarios where optically thick stratiform cloud contains light precipitation (Xu and Rutledge 2014). The terms that lead to the evolution of $B_{L}$ [Eq. (46)] are shown in the middle and bottom panels of Fig. 7. The maximum in $B_{L}$ is preceded by a positive $\partial_{t} B_{L}$, which attains a maximum amplitude at lag $-3 \mathrm{~h}$. The $3-12 \mathrm{~h}$ time scale for increase in $B_{L}$ is 
(a) Horizontal moisture advection in LFT

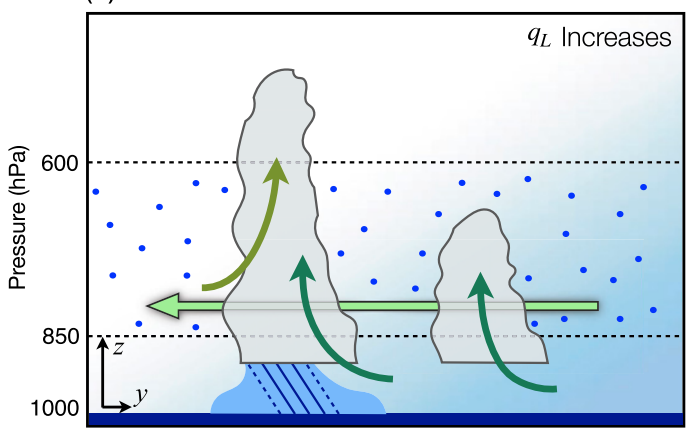

(c)

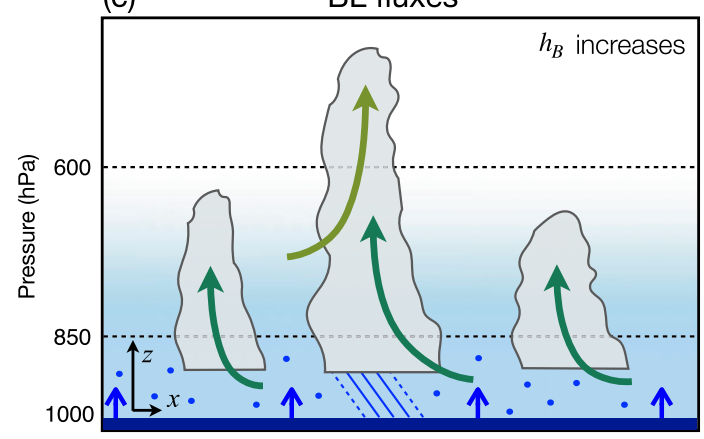

(e) Steady Isentropic Lifting

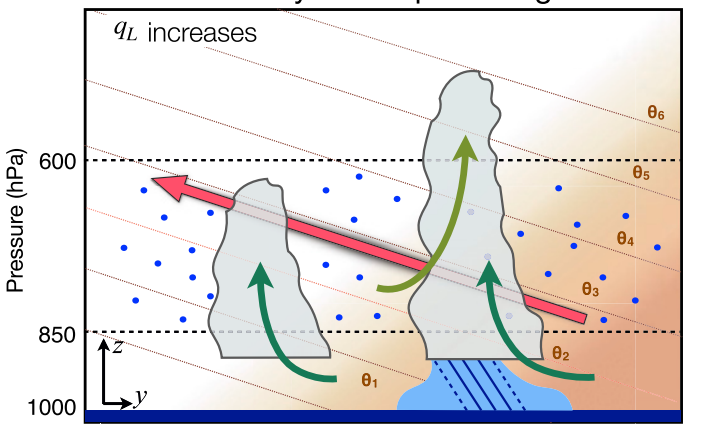

(b) Horizontal moisture advection in $\mathrm{BL}$

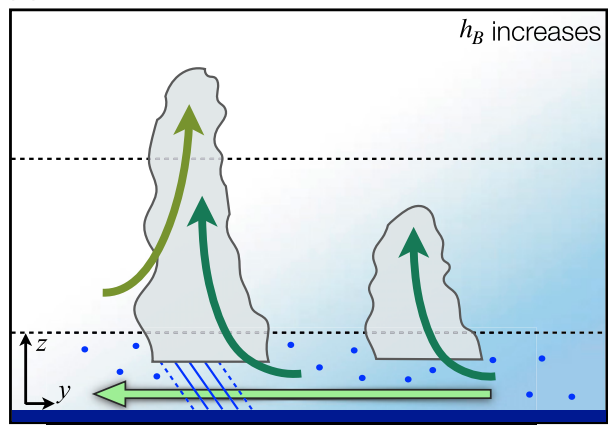

(d) Cloud radiative heating

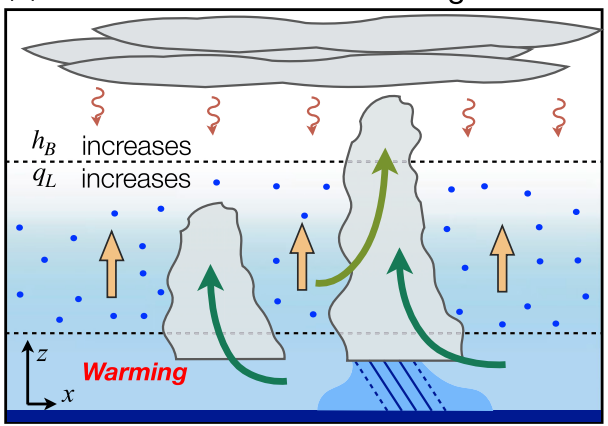

(f)

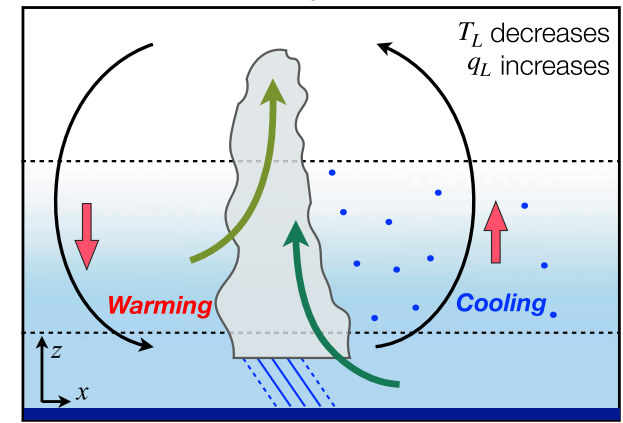

$\uparrow \omega_{a} \uparrow \omega_{c B} \uparrow \omega_{c L} \uparrow \omega_{r} \zeta L W \cdot \because$ Moistening

FIG. 6. Schematic describing processes that increase $B_{L}$ in synoptic-scale tropical motion systems. The way each process modulates the individual terms that contribute to $B_{L}$ [Eq. (4)] are shown at the top of each panel. (a)-(d),(f) The blue background shading denotes the mean distribution of moisture. (e) The red shading denotes the distribution of temperature. Note that (a), (b), and (e) are latitude-height cross sections that represent meridional moisture and temperature gradients found in the tropics. The other panels are longitude-height cross sections.

consistent with the time scale of convective buildup on short time scales during DYNAMO (third column of Table 3 in Powell and Houze 2013).

When considering the processes that lead to the evolution of $B_{L}$ (middle and bottom panels of Fig. 7), we find that largest contributor was term $C$. This result is consistent with Fig. 5, which shows that the time series of $\omega_{a}$ and $\omega_{Q}$ are often in quadrature. It indicates that convection was often preceded by adiabatic moistening and cooling of the LFT. The large amplitude of term $C$ and the fast time scale in which destabilization occurred is suggestive of inertio-gravity waves (Mapes 2000; Raymond and Fuchs 2007) similarly to features depicted in Fig. 6f and documented by Zuluaga and Houze (2013) and Yu et al. (2018) in DYNAMO radar data.

The second largest source of $B_{L}$ is term $E$. We can elucidate the processes that lead to convective moistening at this time by approximating both updrafts and downdrafts as entraining plumes, as some cumulus parameterizations do (Del Genio et al. 2012; Park 2014). By expressing the net vertical MSE advection by convection in terms of the detrainment rates of convective updrafts and downdrafts we obtain the following: 


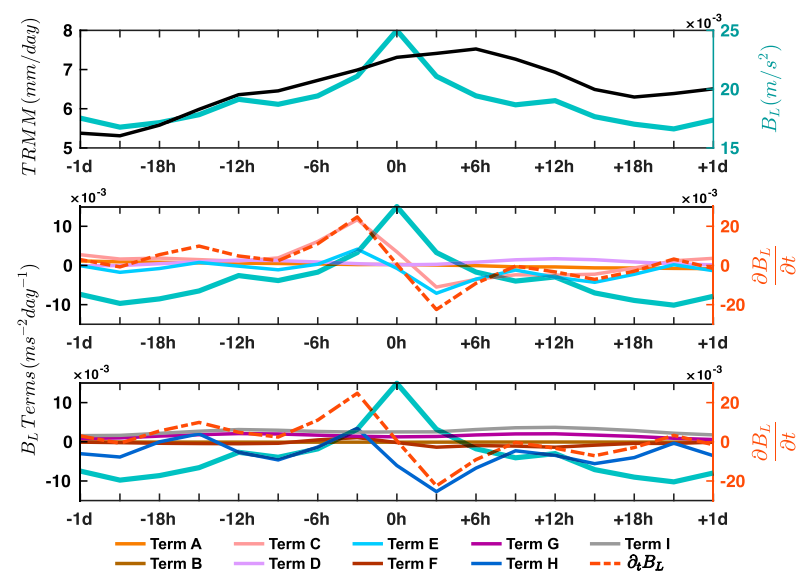

FIG. 7. Lag regression based on a $B_{L}$ time series obtained from sounding data from DYNAMO northern array. (top) The $B_{L}$ (blue-green) and TRMM $3 \mathrm{~b} 42$ rainfall rate $\left(\mathrm{mm} \mathrm{day}^{-1}\right)$ for NSA. (middle) the LFT terms in Eq. (46). (bottom) The DBL terms. In the middle and bottom panels $\partial_{t} B_{L}$ is shown as a dark orange dashed line, in units of $\mathrm{m} \mathrm{s}^{-2} \mathrm{day}^{-1}$. Anomalies are scaled to a $0.025 \mathrm{~m} \mathrm{~s}^{-2}$ perturbation in $B_{L}$ at lag hour 0 . Note that the axis for $\partial_{t} B_{L}$ (right $y$ axis) has been compressed to facilitate comparison between the terms in Eq. (46).

$$
\overline{-\omega_{c} \frac{\partial m}{\partial p}} \simeq \omega_{d} \delta_{d}\left(m_{d}-m\right)-\omega_{u} \delta_{u}\left(m_{u}-m\right),
$$

where $\delta$ is the detrainment rate, and the subscripts ${ }_{u}$ and ${ }_{d}$ indicate updrafts and downdrafts, respectively. Details on how Eq. (49) is obtained are shown in appendix C. Given that $\delta>0$, $\omega_{u}<0, \omega_{d}>0$, and given that $m_{d}<m$ and $m_{u}>m$, it follows that convection moistens the LFT if the moistening from updraft detrainment exceeds the drying from downdraft detrainment. Thus, the positive term $E$ at lag hour -3 is due to detrainment of updrafts in the LFT, possibly from shallow or cumulus congestus convection. Equivalently, in terms of Eq. (30) and Eq. (46), $Q_{2}$ is negative in the LFT at lag hour -3 , which contributes to a positive term $E$.

Following the maximum in $B_{L}$, a negative $\partial_{t} B_{L}$ is seen, with a maximum amplitude occurring at lag $+3 \mathrm{~h}$. At this time, both terms $C$ and $E$ become negative, indicating adiabatic compression and drying of the LFT by downdrafts. Both of these LFT processes contribute to roughly half of the removal of $B_{L}$ at this time. The other half of the stabilization comes from term $H$, indicating that downdrafts are stabilizing the DBL, as indicated by Eq. (49). The fact that the total negative $B_{L}$ tendency is equally split by contributions from the DBL and LFT underscores the importance of processes occurring within the whole lower troposphere in eliminating convective instability. Other terms in Eq. (46) are smaller in amplitude and contribute less to the evolution of $B_{L}$ at the time scale shown.

It is worth noting that $B_{L}$ remains positive in the two-day lag regression shown in Fig. 7, suggesting that the maximum in $B_{L}$ occurs within an envelope of enhanced $B_{L}$. We investigate the processes that lead to this enhancement of $B_{L}$ by including a lag regression from lag day -10 to lag day 10 , shown in Fig. 8, and smoothing all the terms by a 2 -day running mean. The

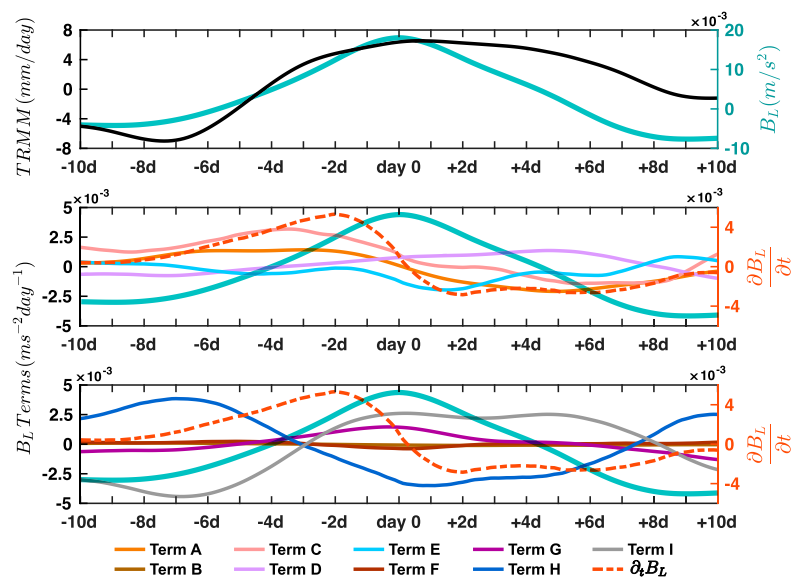

FIG. 8. As in Fig. 7, but ranging from lag day -10 to lag day 10. All the lines shown are smoothed with a 2-day running mean. Note that the limits of the abscissa in the middle and bottom panels are smaller than those in Fig. 7.

evolution of $B_{L}$ and TRMM precipitation follow an analogous pattern to that shown in Fig. 7, with TRMM precipitation slightly lagging $B_{L}$. The $B_{L}$ tendency follows a similar evolution to that seen in Fig. 7, but stretched over the 10-day period. The tendency is a maximum 1-2 days prior to the maximum in $B_{L}$. A minimum in the $B_{L}$ tendency is observed at lag +1 days. The time scale in which $B_{L}$ builds up and is eliminated is consistent with the time scale of the MJO events observed during DYNAMO.

When considering the processes that lead to the evolution of $B_{L}$, we see that the dominant terms are terms $\mathrm{A}$ and $\mathrm{C}$. Both these terms closely follow the $B_{L}$ tendency. Term $C$ is the largest $B_{L}$ source term prior to the $B_{L}$ maximum, followed by term $A$. In contrast, term $A$ is the largest sink of $B_{L}$ after $B_{L}$ is a maximum. Overall, it can be argued that both terms contribute nearly equally to the evolution of $B_{L}$ at these time scales.

Besides terms $A$ and $C$, it can be seen that term $G$ plays an important role in the maintenance of the $B_{L}$ on time scales longer than a day. It is well documented that radiative heating plays an important role in the MJO, but it is interesting that is the DBL radiative heating contribution that dominates at lag day 0 . This result is consistent with Fig. 8 of Wolding et al. (2016). A small, but positive contribution from term D is seen at lag days $+2-7$, likely in association with elevated stratiform convection, in agreement with previous studies (Wang et al. 2016; Ciesielski et al. 2017).

Last, we find that terms $H$ and $I$ are significant, but these DBL contributions along with term $G$ largely cancel one another (bottom panel of Fig. 8) such that the evolution of $\partial_{t} B_{L}$ matches the LFT terms $A$ and $C$ fairly closely (middle panel of Fig. 8). That terms $H$ and $I$ nearly cancel one another is qualitatively consistent with the notion that the DBL adjusts to BLQE on a time scale shorter than a day (Raymond 1995; Hansen et al. 2019).

Term $E$ does not contribute significantly to the buildup of $B_{L}$, but is a significant contributor to the removal of $B_{L}$ from lag day -1 to lag day +7 . When terms $E, H$, and $I$ are 


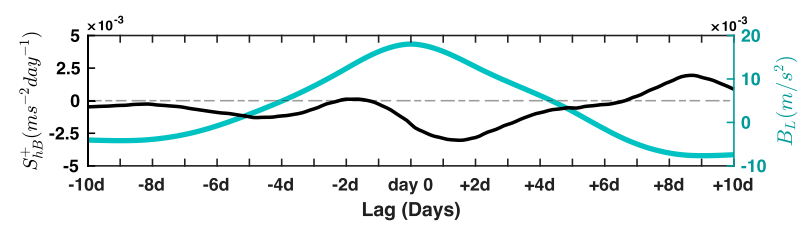

FIG. 9. As in the top panel of Fig. 8, except the black line shows $S_{h B}^{+}$, the sum of terms $E, H$, and $I$ in Eq. (46).

considered together as $S_{h B}^{+}$we see that the BL source surplus is generally negative, indicating that at time scales longer than a day, vertical MSE advection by convection removes more $B_{L}$ than what is supplied by BL sources of ME (Fig. 9).

\section{Conclusions}

In this study, we build upon a growing literature that indicates that tropical deep convection is sensitive to fluctuations in convective instability (CAPE/CIN) and that moisture plays an important role in its occurrence and organization (Fuchs and Raymond 2002; Frierson et al. 2004; Kuo et al. 2017; among others). The framework is based on the precipitation-buoyancy relationship developed by AN18 and expanded upon by AAN. In this framework, precipitation is proportional to the buoyancy of a plume that rises above the DBL (carrying its $\theta_{e}$ ) and entrains environmental air through a deep inflow profile as it ascends in the LFT.

The precipitation-buoyancy relation is used to consolidate the "relaxed" WTG approximation (Sobel et al. 2001; Raymond and Zeng 2005), which allows for temperature fluctuations and prognostic moisture into a single "plume buoyancy equation" [Eq. (46)]. This equation shows that fluctuations in moisture and temperature contribute roughly equally to the evolution of the LFT averaged plume buoyancy $B_{L}$ [Eq. (47)].

We examined the processes that lead to the evolution of $B_{L}$ using sounding data from DYNAMO sounding arrays (Ciesielski et al. 2014). On the basis of linear regression analysis, we find that, at the time scale of a day, the buildup of $B_{L}$ is associated with cooling and moistening of the LFT from departures from WTG, likely in association with adiabatic lifting from gravity waves. The peak in the $B_{L}$ tendency occurs $3 \mathrm{~h}$ prior to the $B_{L}$ maximum. TRMM $3 \mathrm{~B} 42$ rainfall peaks up to $6 \mathrm{~h}$ after the maximum in $B_{L}$. While this temporal shift could be due to discrepancies in the datasets, a delay in the peak and subsequent decay of precipitation suggests that short time scales other than those accounted for by $B_{L}$ may play a role in rainfall, such as the time for deep convective plume growth, production of stratiform rain, or dynamical effects. After the peak in $B_{L}$, warming and drying by departures from WTG, likely from adiabatic compression, and drying of the LFT and DBL by convection eliminate $B_{L}$.

When considering variations in $B_{L}$ at the intraseasonal time scale, we find that horizontal moisture advection and cooling and moistening from adiabatic lifting in the LFT are the dominant terms contributing to $\partial_{t} B_{L}$. The former process has been well documented for the MJO events that occurred during DYNAMO (Sobel et al. 2014; Yokoi and Sobel 2015). The latter is somewhat surprising, and suggests that departures from WTG may play an important role in the MJO. However, it is unclear whether adiabatic lifting is important only for the MJO events that were documented during DYNAMO since these events exhibited a time scale closer to 30 days, a shorter time scale than what is considered typical for the MJO (40-50 days). A scale analysis study by Adames et al. (2019) indicates that the amplitude of adiabatic motions (i.e., the temperature tendency) scale with the square of the wave's phase speed [see their Eq. (14)]. Thus, adiabatic motions should be much weaker in slower-propagating MJO events. However, studies by Powell $(2016,2017)$ and Haertel et al. (2015) have suggested that circumnavigating Kelvin waves, and the cooling of the troposphere associated with them, play an important role in the initiation of at least some MJO events. Considering that the DYNAMO array was located in the region of MJO initiation, then this result may not be surprising, as it may reflect the signature of such a wave before it becomes more coupled to diabatic heating. Nonetheless, this is a result that warrants further study.

There are a few caveats to this study. The centered difference scheme applied to the estimation of the static stability $S_{p}$ can result in numerical errors in the calculation of $\omega_{Q}$, which in turn results in uncertainty in the large-scale adiabatic vertical motion term $\omega_{a}$. Studies that use so-called spectral WTG method of calculating diabatically induced vertical motions indicate that traditional means tend to underestimate $\omega_{Q}$ (Herman and Raymond 2014; Wang et al. 2016). Thus, $\omega_{Q}$ may be underestimated and $\omega_{a}$ overestimated in this study. Comparing the difference between the terms calculated via Eq. (46) using the methods shown herein versus using spectral WTG may be useful.

It is important to note that our equations do not have an explicit representation of different cloud types, opting for a simplified representation of convection based on a single deep plume. Even though we do not make this distinction, the equations for $B_{L}$ bear some similarity to the congestus and stratiform heating equations described by Khouider and Majda (2006, 2008) [their Eqs. (2.7) and (2.8)]. Additionally, our Eq. (6) resembles their equation for precipitation [their Eqs. (2.6) and (2.9)]. The framework presented here does not only validate the foundations of the multicloud models used by Khouider and Majda (2006, 2008) and Khouider and Majda (2016) (among others) but also can be used to tune their model and understand the processes in which these models represent convectively coupled waves.

In addition, we do not include upper-tropospheric processes in this framework for simplicity. Schiro et al. (2018) showed that including the upper troposphere's contribution to the precipitation-buoyancy relation yields similar results to just analyzing the lower troposphere. This result is valid when entrainment in this layer is small, so the effects of uppertropospheric humidity are small. The similarity of these results occurs because temperature tends to be strongly correlated between the upper and lower free troposphere. Integrating the plume buoyancy through the entire troposphere changes its 
magnitude by including virtual temperature difference between plume environment in the upper layer, but most of the variability is not independent of that included in the lower-tropospheric variables. The adjustment processes discussed here in terms of lower-free-tropospheric variables should thus extend to the full troposphere. It is possible that at the next level of refinement, independent fluctuations of temperature, humidity, vertical motions and freezing processes including aerosol effects (Rosenfeld et al. 2008) in the upper troposphere can play a significant role in precipitation, as has been suggested for the observed relationship between the MJO and the QBO (Son et al. 2017; Martin et al. 2019). Developing empirical and theoretical formulations to include these could be a fruitful direction for future work.

Finally, although the $B_{L}$ equation from which we derive its tendency can be utilized to predict the destabilization of the troposphere that leads to convective onset, the framework presented only considers the thermodynamic structure of the atmosphere on precipitation. However, dynamic factors, such as low-level convergence or vertical wind shear, also impact vertical velocities found in convective updrafts, and thus probably contribute to the variance in rain rates that is observed at high $B_{L}$. Thus, while our framework is useful for describing how various processes that alter the thermodynamic structure of the atmosphere impact rainfall, a more complete expression for tropical precipitation evolution would include both the $B_{L}$ tendency and other terms related to large-scale dynamic processes.

While the "plume buoyancy equation" may seem complex, especially when compared to budgets such as columnintegrated MSE, it nonetheless provides a lucid picture of convective destabilization. Furthermore, it shows that departures from quasi equilibrium or WTG can play a key role in the destabilization of the troposphere, which is not as clear when analyzing MSE budgets (see Table 3). Related theoretical work in AAN elaborates on the time scales of adjustment of $B$ toward QE or WTG. Thus, using the plume buoyancy equation is complementary to using standard moisture or MSE budgets when considering convectively coupled tropical motion systems, providing insight into the fluctuations that yield strong convective events, while the MSE budget can be helpful for understanding the envelope of these (AAN; Neelin and Yu 1994; Adames et al. 2019; Ahmed et al. 2021). The framework presented here may also be used for intercomparison of model representation of tropical deep convection.

Acknowledgments. ÁFA was supported by the National Science Foundation (NSF) Grant AGS-1841559. FA And JDN were supported in part by NSF AGS-1540518 and National Atmospheric and Oceanic Administration Grant NA18OAR4310280. ÁFA would like to thank Brandon Wolding, Kuniaki Inoue, Hannah Zanowski, and Daehyun Kim for discussions that helped organize the contents of this manuscript. We also would like to thank George Kiladis for providing us most of the sounding data used in this study.

\section{APPENDIX A}

\section{Derivation of the Plume Buoyancy}

The plume buoyancy shown in Eq. (1a) can be obtained directly from the traditional definition of buoyancy based on potential temperature:

$$
B \simeq g \frac{T_{u}-T}{T}
$$

where $T_{u}$ is the temperature of the rising plume and $T$ is the environmental temperature. Note that a more accurate definition of buoyancy includes the virtual effect of moisture and contributions from liquid water and hydrometeors (Houze 2014; Seeley and Romps 2016). It will be useful to write $B$ in the following form:

$$
B \simeq g \frac{\delta T}{T},
$$

where $\delta T=T_{u}-T$. We can express $B$ in terms of the saturation equivalent potential temperature by using its approximate definition:

$$
\theta_{e}^{*}=\theta \exp \left(\frac{L q^{*}}{c_{p} T}\right) .
$$

Noting that $\theta_{e}^{*}=\theta_{e}^{*}\left[p, T, q^{*}(T)\right]$, we can write $\delta T$ as

$$
\delta \theta_{e}^{*}=\delta T\left(\frac{\delta \theta_{e}^{*}}{\delta T}+\frac{\delta \theta_{e}^{*}}{\delta q^{*}} \frac{\delta q^{*}}{\delta T}\right) .
$$

We can use the Clausius-Clapeyron equation, which can be approximated in terms of $q^{*}$ as

$$
\frac{\delta q^{*}}{\delta T} \simeq \frac{L q^{*}}{R_{v} T^{2}}
$$

to further simplify Eq. (A6) into the following form:

$$
\delta \theta_{e}^{*}=\delta T \frac{\delta \theta_{e}^{*}}{\delta T}\left(1+\frac{L q^{*}}{R_{v} T^{2}}\right),
$$

where the parenthetical terms are condensed into $\kappa$ following Eq. (1b). Differentiation of Eq. (A6) yields the following approximate relation:

$$
\delta \theta_{e}^{*} \simeq\left(\frac{p_{s}}{p}\right)^{R_{d} / c_{p}} \exp \left(\frac{L q^{*}}{c_{p} T}\right) \kappa \delta T .
$$

We can use (A3) and Eq. (A7) to express Eq. (A1) in terms of $\theta_{e}^{*}$, which yields the following expression:

$$
B \simeq g \frac{\theta_{e u}^{*}-\theta_{e}^{*}}{\kappa \theta_{e}^{*}},
$$

which is the buoyancy expression defined in Eq. (6) in Raymond (1994). For the final step we recall that the entraining plume model is used to approximate the behavior of rising cumuliform clouds. Assuming the air within clouds is saturated, it follows that $\theta_{e u}^{*}=\theta_{e u}$. By using this definition we obtain the relationship shown in Eq. (1a). It is worth noting that Moorthi and Suarez (1992) use a similar approximation to express DSE in terms of MSE in their relaxed Arakawa-Schubert scheme. 

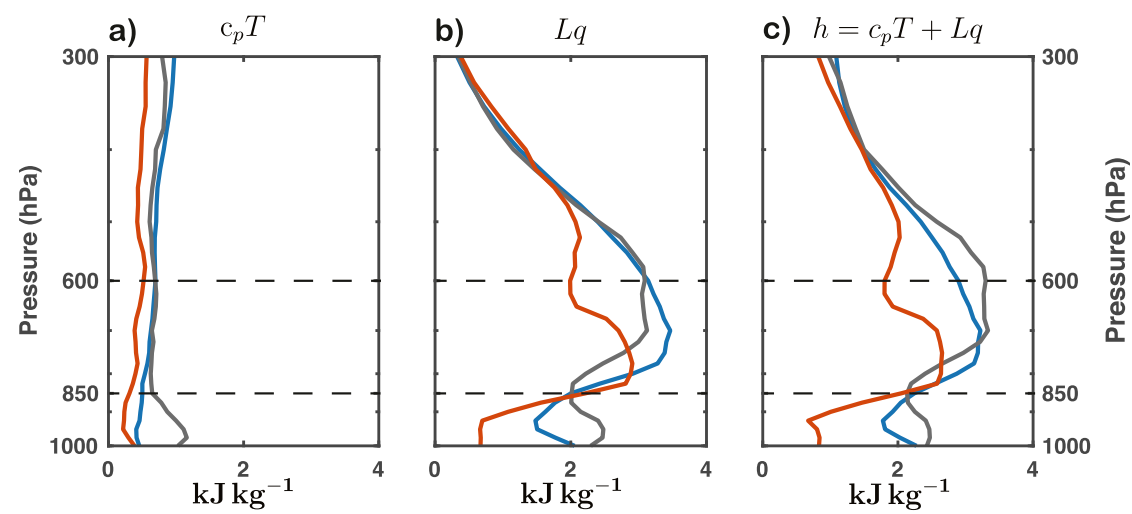

d) $s=c_{p} T+\Phi$

e)
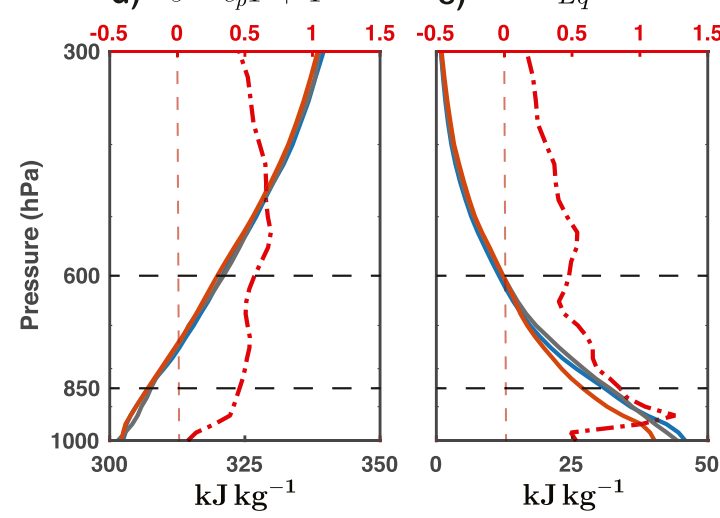

f) $s+L q$

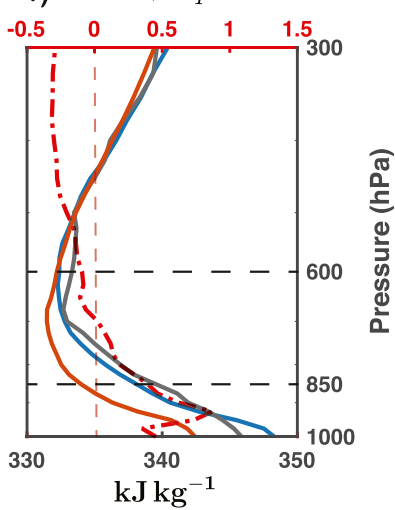

FIG. B1. (top) Standard deviation of daily-mean (a) internal energy $c_{p} T$, (b) latent energy $L q$, and $(c)$ moist enthalpy $(h)$ from sounding data from Majuro $\left(7.1^{\circ} \mathrm{N}, 171.4^{\circ} \mathrm{E}\right.$; blue), Manaus $\left(3.2^{\circ} \mathrm{S}, 59.9^{\circ} \mathrm{W}\right.$; gray) and $\mathrm{Gan}\left(0.6^{\circ} \mathrm{S}, 73.1^{\circ} \mathrm{E}\right.$; red). (bottom) As in the top row, but showing the climatological-mean vertical profiles of (d) DSE (s), (e) Lq, and (f) MSE. The mean vertical gradient of the profiles, in units of $\mathrm{J} \mathrm{kg}^{-1} \mathrm{~Pa}^{-1}$, in (d)-(f) is shown as a dot-dashed line.

\section{APPENDIX B}

\section{Soundings}

The top row in Fig. B1 shows the vertical profiles of variability in $T, q$, and $h$. It shows that variability in temperatures in the tropics are on the order of $1 \mathrm{~K}$, while variability in $q$ is on the order of $1 \mathrm{~g} \mathrm{~kg}^{-1}$. The vertical gradients of DSE, $L q$ and MSE are shown in the bottom row. The mean gradients are very similar across the three sounding sites analyzed. The DSE and $L q$ vertical gradients are on the order of $0.5 \mathrm{~J} \mathrm{~kg}^{-1} \mathrm{~Pa}^{-1}$ over the LFT, while the layer-averaged MSE gradient is on the order of $0.1 \mathrm{~J} \mathrm{~kg}^{-1} \mathrm{~Pa}^{-1}$. We can estimate $M_{B}$ from Fig. B1f to be on the order of $0.3 \mathrm{~J} \mathrm{~kg}^{-1}$. These estimates are used in the scaling of the equations shown in Table 3 and Eq. (47).

\section{APPENDIX C}

\section{Interpretation of the Vertical Transport of MSE by Convection}

Evaluation of Eq. (46) reveals that convective motions play an important role in its evolution. As discussed previously, MSE advection by $\omega_{c}$ contains a contribution from large-scale motions and subgrid-scale motions. Understanding the net
MSE advection by convection requires understanding the net impact that the subgrid-scale eddies have on this process. Following Raymond (1997), we assume that convective motions can be broken into updraft and downdraft vertical velocities, $\omega_{u}$ and $\omega_{d}$, respectively,

$$
\begin{aligned}
& \omega_{c} \simeq \omega_{u}+\omega_{d}, \\
& \omega_{u}=-S_{p}^{-1} L c, \\
& \omega_{d}=S_{p}^{-1} L e,
\end{aligned}
$$

where the updraft vertical velocity is the velocity that balances latent heating by condensation, while the downdraft vertical velocity balances evaporation. In defining $\omega_{u}$ and $\omega_{d}$ we are neglecting the contribution of subgrid-scale eddies to $\omega_{c}$. This approximation is appropriate since scaling of $Q_{c}$ indicates that $\partial_{p} \overline{\omega^{\prime} s^{\prime}} \ll L(c-e)$. Since $s^{\prime}$ is the departure of temperature within convection from that of the environment, this approximation is consistent with the application of WTG balance.

In addition to the decomposition of $\omega_{c}$, we will decompose the vertical eddy flux of MSE into contributions from updrafts and downdrafts, respectively,

$$
\overline{\omega^{\prime} m^{\prime}} \simeq\left(\overline{\omega^{\prime} m^{\prime}}\right)_{u}+\left(\overline{\omega^{\prime} m^{\prime}}\right)_{d} .
$$


Following Yanai et al. (1973), we can write the vertical eddy flux as the departure of vertical motion in convection from its environment value $\left(\omega_{e}\right)$ the departure of MSE from its environmental value. Furthermore, because vertical motions in convection are usually much larger than those of the surrounding environment $\left(\omega_{c} \gg \omega_{e}\right)$ and the environment MSE is approximately that of the domain $(m)$, we obtain the following:

$$
\begin{aligned}
& \left(\overline{\omega^{\prime} m^{\prime}}\right)_{u} \simeq \omega_{u}\left(m_{u}-m\right), \\
& \left(\overline{\omega^{\prime} m^{\prime}}\right)_{d} \simeq \omega_{d}\left(m_{d}-m\right) .
\end{aligned}
$$

We can elucidate the processes that lead to LFT moistening and drying by convectively driven vertical MSE advection by following a decomposition similar to Eq. (C2) and inserting Eq. (C3) into Eq. (30), yielding

$$
\begin{aligned}
-\overline{\omega_{c} \frac{\partial m}{\partial p}} & =-\overline{\omega_{u} \frac{\partial m}{\partial p}}-\overline{\omega_{d} \frac{\partial m}{\partial p}}, \\
-\overline{\omega_{u} \frac{\partial m}{\partial p}} & =-\omega_{u} \frac{\partial m_{u}}{\partial p}-\left(m_{u}-m\right) \frac{\partial \omega_{u}}{\partial p}, \\
-\overline{\omega_{d} \frac{\partial m}{\partial p}} & =-\omega_{d} \frac{\partial m_{d}}{\partial p}-\left(m_{d}-m\right) \frac{\partial \omega_{d}}{\partial p},
\end{aligned}
$$

where we note that the vertical advection of environment MSE by updrafts and downdrafts is cancelled. We can gain further insight onto the right-hand-side terms in Eq. (C4) by following Siebesma et al. (2007) and defining the updraft mass flux in terms of entrainment $\varepsilon$ and detrainment $\delta$ rates, respectively,

$$
\frac{1}{\omega_{u}} \frac{\partial \omega_{u}}{\partial p}=\delta_{u}-\varepsilon_{u}
$$

The downdraft mass flux can be defined in an analogous way. Following Betts (1975), we can replace the second term on the right-hand side of Eq. (C4) with Eq. (C5). By assuming that updrafts and downdrafts are approximately entraining plumes, we can use Eq. (13) in Betts (1975) to obtain Eq. (49). While the framework of AN18 suggests that updrafts can be approximated as entraining plumes, they do not analyze downdrafts. However, it is worth noting that observations indicate that downdrafts entrain environmental air as well (Schiro and Neelin 2018), and approximating them as entraining plumes may be reasonable.

\section{REFERENCES}

Adames, Á. F., 2017: Precipitation budget of the Madden-Julian oscillation. J. Atmos. Sci., 74, 1799-1817, https://doi.org/ 10.1175/JAS-D-16-0242.1.

_ , and Y. Ming, 2018: Moisture and moist static energy budgets of South Asian monsoon low pressure systems in GFDL AM4.0. J. Atmos. Sci., 75, 2107-2123, https://doi.org/10.1175/JAS-D-170309.1.

, D. Kim, S. K. Clark, Y. Ming, and K. Inoue, 2019: Scale analysis of moist thermodynamics in a simple model and the relationship between moisture modes and gravity waves. J. Atmos. Sci., 76, 3863-3881, https://doi.org/10.1175/JAS-D-19-0121.1.
Ahmed, F., and J. D. Neelin, 2018: Reverse engineering the tropical precipitation-buoyancy relationship. J. Atmos. Sci., 75, 1587-1608, https://doi.org/10.1175/JAS-D-17-0333.1.

— Á. F. Adames, and J. D. Neelin, 2020: Deep convective adjustment of temperature and moisture. J. Atmos. Sci., 77, 2163-2186, https://doi.org/10.1175/JAS-D-19-0227.1.

, J. D. Neelin, and Á. F. Adames, 2021: Quasi-equilibrium and weak temperature gradient balances in an equatorial betaplane model. J. Atmos. Sci., 78, 209-227, https://doi.org/10.1175/ JAS-D-20-0184.1.

Arakawa, A., and W. H. Schubert, 1974: Interaction of a cumulus cloud ensemble with the large-scale environment, part I. J. Atmos. Sci., 31, 674-701, https://doi.org/10.1175/ 1520-0469(1974)031<0674:IOACCE > 2.0.CO;2.

Betts, A. K., 1975: Parametric interpretation of trade-wind cumulus budget studies. J. Atmos. Sci., 32, 1934-1945, https://doi.org/10.1175/1520-0469(1975)032<1934:PIOTWC> 2.0.CO;2.

Bretherton, C. S., and P. K. Smolarkiewicz, 1989: Gravity waves, compensating subsidence and detrainment around cumulus clouds. J. Atmos. Sci., 46, 740-759, https://doi.org/10.1175/ 1520-0469(1989)046<0740:GWCSAD > 2.0.CO;2.

— coupled Walker circulation using the weak temperature gradient approximation. J. Climate, 15, 2907-2920, https://doi.org/ 10.1175/1520-0442(2002)015<2907:ASMOAC >2.0.CO;2.

$\longrightarrow$, and - 2003: The Gill model and the weak temperature gradient approximation. J. Atmos. Sci., 60, 451-460, https://doi.org/ 10.1175/1520-0469(2003)060<0451:TGMATW >2.0.CO;2.

— M. E. Peters, and L. E. Back, 2004: Relationships between water vapor path and precipitation over the tropical oceans. J. Climate, 17, 1517-1528, https://doi.org/10.1175/1520-0442(2004)017<1517: RBWVPA $>2.0 . \mathrm{CO} ; 2$.

Charney, J. G., 1963: A note on large-scale motions in the tropics. J. Atmos. Sci., 20, 607-609, https://doi.org/10.1175/1520-0469(1963) $020<0607$ :ANOLSM $>2.0 . \mathrm{CO} ; 2$.

Chikira, M., 2014: Eastward-propagating intraseasonal oscillation represented by Chikira-Sugiyama cumulus parameterization. Part II: Understanding moisture variation under weak temperature gradient balance. J. Atmos. Sci., 71, 615-639, https:// doi.org/10.1175/JAS-D-13-038.1.

Ciesielski, P. E., and Coauthors, 2014: Quality-controlled upper-air sounding dataset for DYNAMO/CINDY/AMIE: Development and corrections. J. Atmos. Oceanic Technol., 31, 741-764, https:// doi.org/10.1175/JTECH-D-13-00165.1.

—, R. H. Johnson, X. Jiang, Y. Zhang, and S. Xie, 2017: Relationships between radiation, clouds, and convection during DYNAMO. J. Geophys. Res. Atmos., 122, 2529-2548, https://doi.org/10.1002/2016JD025965.

Del Genio, A. D., Y. Chen, D. Kim, and M.-S. Yao, 2012: The MJO transition from shallow to deep convection in CloudSat/CALIPSO data and GISS GCM simulations. J. Climate, 25, 3755-3770, https://doi.org/10.1175/JCLI-D-11-00384.1.

de Rooy, W. C., and Coauthors, 2013: Entrainment and detrainment in cumulus convection: An overview. Quart. J. Roy. Meteor. Soc., 139, 1-19, https://doi.org/10.1002/qj.1959.

de Szoeke, S. P., 2018: Variations of the moist static energy budget of the tropical Indian Ocean atmospheric boundary layer. J. Atmos. Sci., 75, 1545-1551, https://doi.org/10.1175/JAS-D-17-0345.1.

Donner, L. J., and V. T. Phillips, 2003: Boundary layer control on convective available potential energy: Implications for cumulus parameterization. J. Geophys. Res., 108, 4701, https:// doi.org/10.1029/2003JD003773. 
Durre, I., R. S. Vose, and D. B. Wuertz, 2006: Overview of the Integrated Global Radiosonde Archive. J. Climate, 19, 53-68, https://doi.org/10.1175/JCLI3594.1.

Emanuel, K., 1993: The effect of convective response time on WISHE modes. J. Atmos. Sci., 50, 1763-1776, https://doi.org/ 10.1175/1520-0469(1993)050<1763:TEOCRT>2.0.CO;2.

— 1995: The behavior of a simple hurricane model using a convective scheme based on subcloud-layer entropy equilibrium. J. Atmos. Sci., 52, 3960-3968, https://doi.org/10.1175/ 1520-0469(1995)052<3960:TBOASH>2.0.CO;2.

_ 2019 : Inferences from simple models of slow, convectively coupled processes. J. Atmos. Sci., 76, 195-208, https://doi.org/ 10.1175/JAS-D-18-0090.1.

— J. D. Neelin, and C. S. Bretherton, 1994: On large-scale circulations in convecting atmospheres. Quart. J. Roy. Meteor. Soc., 120, 1111-1143, https://doi.org/10.1002/qj.49712051902.

Frierson, D. M., A. J. Majda, and O. M. Pauluis, 2004: Large scale dynamics of precipitation fronts in the tropical atmosphere: A novel relaxation limit. Commun. Math. Sci., 2, 591-626, https:// doi.org/10.4310/CMS.2004.v2.n4.a3.

Fuchs, Ž., and D. J. Raymond, 2002: Large-scale modes of a nonrotating atmosphere with water vapor and cloud-radiation feedbacks. J. Atmos. Sci., 59, 1669-1679, https://doi.org/10.1175/ 1520-0469(2002)059<1669:LSMOAN>2.0.CO;2.

Gao, S., L. Ran, and X. Li, 2006: Impacts of ice microphysics on rainfall and thermodynamic processes in the tropical deep convective regime: A 2D cloud-resolving modeling study. Mon. Wea. Rev., 134, 3015-3024, https://doi.org/10.1175/ MWR3220.1.

Grabowski, W. W., and M. W. Moncrieff, 2004: Moistureconvection feedback in the tropics. Quart. J. Roy. Meteor. Soc., 130, 3081-3104, https://doi.org/10.1256/qj.03.135.

Haertel, P., K. Straub, and A. Budsock, 2015: Transforming circumnavigating kelvin waves that initiate and dissipate the Madden-Julian oscillation. Quart. J. Roy. Meteor. Soc., 141, 1586-1602, http://doi.org/10.1002/qj.2461.

Hannah, W. M., 2017: Entrainment versus dilution in tropical deep convection. J. Atmos. Sci., 74, 3725-3747, https://doi.org/10.1175/ JAS-D-16-0169.1.

_ B B. E. Mapes, and G. S. Elsaesser, 2016: A Lagrangian view of moisture dynamics during DYNAMO. J. Atmos. Sci., 73, 1967-1985, https://doi.org/10.1175/JAS-D-15-0243.1.

Hansen, Z. R., L. E. Back, and P. Zhou, 2019: Boundary layer quasi-equilibrium limits convective intensity enhancement from the diurnal cycle in surface heating. J. Atmos. Sci., 77, 217-237, https://doi.org/10.1175/JAS-D-18-0346.1.

Hartmann, D. L., 2015: Global Physical Climatology. Vol. 103, Newnes, 498 pp.

Herman, M. J., and D. J. Raymond, 2014: WTG cloud modeling with spectral decomposition of heating. J. Adv. Model. Earth Syst., 6, 1121-1140, https://doi.org/10.1002/2014MS000359.

Hersbach, H., and Coauthors, 2019: Global reanalysis: Goodbye ERAInterim, hello ERA5. ECMWF Newsletter, No. 159, ECMWF, Reading, United Kingdom, 17-24, https://www.ecmwf.int/sites/ default/files/elibrary/2019/19027-global-reanalysis-goodbye-erainterim-hello-era5.pdf.

Houghton, H. G., and H. E. Cramer, 1951: A theory of entrainment in convective currents. J. Meteor., 8, 95-102, https://doi.org/ 10.1175/1520-0469(1951)008<0095:ATOEIC >2.0.CO;2.

Houze, R. A., Jr., 2014: Cloud Dynamics. Vol. 104, Academic Press, $496 \mathrm{pp}$.

Huffman, G. J., and Coauthors, 2007: The TRMM Multisatellite Precipitation Analysis (TMPA): Quasi-global, multiyear, combined-sensor precipitation estimates at fine scales. J. Hydrometeor., 8, 38-55, https://doi.org/10.1175/JHM560.1.

Inoue, K., and L. Back, 2015: Column-integrated moist static energy budget analysis on various time scales during TOGA COARE. J. Atmos. Sci., 72, 1856-1871, https://doi.org/10.1175/JAS-D-140249.1.

Johnson, R. H., T. M. Rickenbach, S. A. Rutledge, P. E. Ciesielski, and W. H. Schubert, 1999: Trimodal characteristics of tropical convection. J. Climate, 12, 2397-2418, https://doi.org/10.1175/ 1520-0442(1999)012<2397:TCOTC>2.0.CO;2.

—_, P. E. Ciesielski, J. H. Ruppert, and M. Katsumata, 2015: Sounding-based thermodynamic budgets for DYNAMO. J. Atmos. Sci., 72, 598-622, https://doi.org/10.1175/JAS-D14-0202.1.

,-- , and T. M. Rickenbach, 2016: A further look at Q1 and Q2 from TOGA COARE. Multiscale Convection-Coupled Systems in the Tropics: A Tribute to Dr. Michio Yanai, Meteor. Monogr., No. 56, Amer. Meteor. Soc., https://doi.org/10.1175/ AMSMONOGRAPHS-D-15-0002.1.

Khouider, B., and A. J. Majda, 2006: A simple multicloud parameterization for convectively coupled tropical waves. Part I: Linear analysis. J. Atmos. Sci., 63, 1308-1323, https://doi.org/ 10.1175/JAS3677.1.

$\longrightarrow$, and —, 2008: Multicloud models for organized tropical convection: Enhanced congestus heating. J. Atmos. Sci., 65 , 895-914, https://doi.org/10.1175/2007JAS2408.1.

_ , and —, 2016: Models for multiscale interactions. Part I: A multicloud model parameterization. Multiscale ConvectionCoupled Systems in the Tropics: A Tribute to Dr. Michio Yanai, Meteor. Monogr., No. 56, Amer. Meteor. Soc., https:// doi.org/10.1175/AMSMONOGRAPHS-D-15-0004.1.

Kiladis, G. N., C. D. Thorncroft, and N. M. J. Hall, 2006: Threedimensional structure and dynamics of African easterly waves. Part I: Observations. J. Atmos. Sci., 63, 2212-2230, https:// doi.org/10.1175/JAS3741.1.

—, M. C. Wheeler, P. T. Haertel, K. H. Straub, and P. E. Roundy, 2009: Convectively coupled equatorial waves. Rev. Geophys., 47, RG2003, https://doi.org/10.1029/2008RG000266.

Kim, H., F. Vitart, and D. E. Waliser, 2018: Prediction of the Madden-Julian oscillation: A review. J. Climate, 31, 94259443, https://doi.org/10.1175/JCLI-D-18-0210.1.

Kingsmill, D. E., and R. A. Houze Jr., 1999: Thermodynamic characteristics of air flowing into and out of precipitating convection over the west Pacific warm pool. Quart. J. Roy. Meteor. Soc., 125, 1209-1229, https://doi.org/10.1002/qj.1999.49712555606.

Kuang, Z., 2008: Modeling the interaction between cumulus convection and linear gravity waves using a limited-domain cloud system-resolving model. J. Atmos. Sci., 65, 576-591, https:// doi.org/10.1175/2007JAS2399.1.

_ 2010: Linear response functions of a cumulus ensemble to temperature and moisture perturbations and implications for the dynamics of convectively coupled waves. J. Atmos. Sci., 67, 941-962, https://doi.org/10.1175/2009JAS3260.1.

Kuo, Y.-H., J. D. Neelin, and C. R. Mechoso, 2017: Tropical convective transition statistics and causality in the water vaporprecipitation relation. J. Atmos. Sci., 74, 915-931, https:// doi.org/10.1175/JAS-D-16-0182.1.

- _ - - , and K. A. Schiro, 2018: Convective transition statistics over tropical oceans for climate model diagnostics: Observational baseline. J. Atmos. Sci., 75, 1553-1570, https://doi.org/10.1175/JAS-D-17-0287.1.

Lucas, C., E. J. Zipser, and M. A. Lemone, 1994: Vertical velocity in oceanic convection off tropical Australia. J. Atmos. Sci., 51, 
3183-3193, https://doi.org/10.1175/1520-0469(1994)051<3183: VVIOCO $>2.0 . \mathrm{CO} ; 2$.

Madden, R., and P. Julian, 1972: Description of global scale circulation cells in the tropics with a 40-50 day period. J. Atmos. Sci., 29, 1109-1123, https://doi.org/10.1175/1520-0469(1972) 029<1109:DOGSCC >2.0.CO;2.

Mapes, B. E., 1997: Mutual adjustment of mass flux and stratification profiles. The Physics and Parameterization of Moist Atmospheric Convection, Springer, 399-411, https://doi.org/ 10.1007/978-94-015-8828-7_16.

- 2000: Convective inhibition, subgrid-scale triggering energy, and stratiform instability in a toy tropical wave model. J. Atmos. Sci., 57, 1515-1535, https://doi.org/10.1175/15200469(2000)057<1515:CISSTE > 2.0.CO;2.

_ _ and R. A. Houze Jr., 1993: An integrated view of the 1987 Australian monsoon and its mesoscale convective systems. II: Vertical structure. Quart. J. Roy. Meteor. Soc., 119, 733-754, https://doi.org/10.1002/qj.49711951207.

— , S. Tulich, J. Lin, and P. Zuidema, 2006: The mesoscale convection life cycle: Building block or prototype for large-scale tropical waves? Dyn. Atmos. Oceans, 42, 3-29, https://doi.org/ 10.1016/j.dynatmoce.2006.03.003.

Martin, Z., S. Wang, J. Nie, and A. Sobel, 2019: The impact of the $\mathrm{QBO}$ on MJO convection in cloud-resolving simulations. J. Atmos. Sci., 76, 669-688, https://doi.org/10.1175/JAS-D18-0179.1.

Mechem, D. B., R. A. Houze Jr., and S. S. Chen, 2002: Layer inflow into precipitating convection over the western tropical Pacific. Quart. J. Roy. Meteor. Soc., 128, 1997-2030, https://doi.org/ 10.1256/003590002320603502.

Moorthi, S., and M. J. Suarez, 1992: Relaxed Arakawa-Schubert. A parameterization of moist convection for general circulation models. Mon. Wea. Rev., 120, 978-1002, https://doi.org/10.1175/ 1520-0493(1992) $120<0978:$ RASAPO $>2.0 . C O ; 2$.

Neelin, J. D., and J.-Y. Yu, 1994: Modes of tropical variability under convective adjustment and the Madden-Julian oscillation. Part I: Analytical theory. J. Atmos. Sci., 51, 1876-1894, https://doi.org/10.1175/1520-0469(1994)051<1876:MOTVUC> 2.0.CO;2.

— , O. Peters, J. W.-B. Lin, K. Hales, and C. E. Holloway, 2008: Rethinking convective quasi-equilibrium: Observational constraints for stochastic convective schemes in climate models. Philos. Trans. Roy. Soc., 366A, 2581-2604, https://doi.org/ 10.1098/rsta.2008.0056.

Park, S., 2014: A unified convection scheme (UNICON). Part I: Formulation. J. Atmos. Sci., 71, 3902-3930, https://doi.org/ 10.1175/JAS-D-13-0233.1.

Petty, G. W., 2008: A First Course in Atmospheric Thermodynamics. Sundog Publishing, $337 \mathrm{pp}$.

Powell, S. W., 2016: Updraft buoyancy within and moistening by cumulonimbi prior to MJO convective onset in a regional model. J. Atmos. Sci., 73, 2913-2934, https://doi.org/10.1175/ JAS-D-15-0326.1.

— 2017: Successive MJO propagation in MERRA-2 reanalysis. Geophys. Res. Lett., 44, 5178-5186, https://doi.org/10.1002/ 2017GL073399.

_ 2019: Observing possible thermodynamic controls on tropical marine rainfall in moist environments. J. Atmos. Sci., 76, 37373751, https://doi.org/10.1175/JAS-D-19-0144.1.

—_, and R. A. Houze Jr., 2013: The cloud population and onset of the Madden-Julian oscillation over the Indian Ocean during DYNAMO-AMIE. J. Geophys. Res. Atmos., 118, 11979 11 995, https://doi.org/10.1002/2013JD020421.
Raymond, D. J., 1994: Cumulus convection and the Madden-Julian oscillation of the tropical troposphere. Physica D, 77, 1-22, https://doi.org/10.1016/0167-2789(94)90124-4.

_- 1995: Regulation of moist convection over the west Pacific warm pool. J. Atmos. Sci., 52, 3945-3959, https://doi.org/ 10.1175/1520-0469(1995)052<3945:ROMCOT>2.0.CO;2.

_- 1997: Boundary layer quasi-equilibrium (BLQ). The Physics and Parameterization of Moist Atmospheric Convection, Springer, 387-397, https://doi.org/10.1007/ 978-94-015-8828-7_15.

_ 2000: Thermodynamic control of tropical rainfall. Quart. J. Roy. Meteor. Soc., 126, 889-898, http://doi.org/10.1002/qj.49712656406. , and X. Zeng, 2005: Modelling tropical atmospheric convection in the context of the weak temperature gradient approximation. Quart. J. Roy. Meteor. Soc., 131, 1301-1320, https://doi.org/10.1256/qj.03.97.

— ture modes in a simple atmospheric model. Tellus, 59, 627-640, https://doi.org/10.1111/j.1600-0870.2007.00268.x.

— tropical cyclogenesis. Geophys. Res. Lett., 34, L06811, https:// doi.org/10.1029/2006GL028607.

— , and M. J. Herman, 2011: Convective quasi-equilibrium reconsidered. J. Adv. Model. Earth Syst., 3, 14, https://doi.org/ 10.1029/2011MS000079.

— C. S. Bretherton, and J. Molinari, 2006: Dynamics of the intertropical convergence zone of the east Pacific. J. Atmos. Sci., 63, 582-597, https://doi.org/10.1175/JAS3642.1.

— Ž. Fuchs, S. Gjorgjievska, and S. Sessions, 2015: Balanced dynamics and convection in the tropical troposphere. J. Adv. Model. Earth Syst., 7, 1093-1116, https://doi.org/10.1002/ 2015 MS000467.

Rosenfeld, D., W. L. Woodley, A. Lerner, G. Kelman, and D. T. Lindsey, 2008: Satellite detection of severe convective storms by their retrieved vertical profiles of cloud particle effective radius and thermodynamic phase. J. Geophys. Res., 113, D04208, https://doi.org/10.1029/2007JD008600.

Ruppert, J. H., and C. Hohenegger, 2018: Diurnal circulation adjustment and organized deep convection. J. Climate, 31, 48994916, https://doi.org/10.1175/JCLI-D-17-0693.1.

Rushley, S. S., D. Kim, C. S. Bretherton, and M.-S. Ahn, 2018: Reexamining the nonlinear moisture-precipitation relationship over the tropical oceans. Geophys. Res. Lett., 45, 11331140, https://doi.org/10.1002/2017GL076296.

Russell, J. O. H., A. Aiyyer, and J. D. White, 2020: African easterly wave dynamics in convection-permitting simulations: Rotational stratiform instability as a conceptual model. J. Adv. Model. Earth Syst., 12, e2019MS001706, https:// doi.org/10.1029/2019MS001706.

Sahany, S., J. D. Neelin, K. Hales, and R. B. Neale, 2012: Temperaturemoisture dependence of the deep convective transition as a constraint on entrainment in climate models. J. Atmos. Sci., 69, 1340-1358, https://doi.org/10.1175/JAS-D-11-0164.1.

Schiro, K. A., and J. D. Neelin, 2018: Tropical continental downdraft characteristics: Mesoscale systems versus unorganized convection. Atmos. Chem. Phys., 18, 1997-2010, https://doi.org/10.5194/acp-18-1997-2018.

— vertical structure, and convective transition using deep-inflow mixing. J. Atmos. Sci., 76, 965-987, https://doi.org/10.1175/ JAS-D-18-0122.1.

— F. Ahmed, S. E. Giangrande, and J. D. Neelin, 2018: GoAmazon2014/5 campaign points to deep-inflow approach 
to deep convection across scales. Proc. Natl. Acad. Sci. USA, 115, 4577-4582, https://doi.org/10.1073/pnas.1719842115.

Seeley, J. T., and D. M. Romps, 2016: Tropical cloud buoyancy is the same in a world with or without ice. Geophys. Res. Lett., $\mathbf{4 3}$, 3572-3579, https://doi.org/10.1002/2016GL068583.

Siebesma, A. P., P. M. M. Soares, and J. Teixeira, 2007: A combined eddy-diffusivity mass-flux approach for the convective boundary layer. J. Atmos. Sci., 64, 1230-1248, https://doi.org/ 10.1175/JAS3888.1.

Sobel, A. H., and C. S. Bretherton, 2000: Modeling tropical precipitation in a single column. J. Climate, 13, 4378-4392, https:// doi.org/10.1175/1520-0442(2000)013<4378:MTPIAS>2.0.CO;2.

_ - J. Nilsson, and L. M. Polvani, 2001: The weak temperature gradient approximation and balanced tropical moisture waves. J. Atmos. Sci., 58, 3650-3665, https://doi.org/10.1175/15200469(2001)058<3650:TWTGAA > 2.0.CO;2.

- S. Wang, and D. Kim, 2014: Moist static energy budget of the MJO during DYNAMO. J. Atmos. Sci., 71, 4276-4291, https:// doi.org/10.1175/JAS-D-14-0052.1.

Son, S.-W., Y. Lim, C. Yoo, H. H. Hendon, and J. Kim, 2017: Stratospheric control of the Madden-Julian oscillation. J. Climate, 30, 1909-1922, https://doi.org/10.1175/JCLI-D-16-0620.1.

Stanfield, R. E., and Coauthors, 2016: A quantitative assessment of precipitation associated with the ITCZ in the CMIP5 GCM simulations. Climate Dyn., 47, 1863-1880, https://doi.org/ 10.1007/s00382-015-2937-y.

Stechmann, S. N., and J. D. Neelin, 2011: A stochastic model for the transition to strong convection. J. Atmos. Sci., 68, 2955-2970, https://doi.org/10.1175/JAS-D-11-028.1.

Straub, K. H., and G. N. Kiladis, 2002: Observations of a convectively coupled Kelvin wave in the eastern Pacific ITCZ. J. Atmos. Sci., 59, 30-53, https://doi.org/10.1175/15200469(2002)059<0030:OOACCK > 2.0.CO;2.

Sumi, Y., and H. Masunaga, 2016: A moist static energy budget analysis of quasi-2-day waves using satellite and reanalysis data. J. Atmos. Sci., 73, 743-759, https://doi.org/10.1175/JASD-15-0098.1.

Tang, Y., and Coauthors, 2018: Progress in ENSO prediction and predictability study. Natl. Sci. Rev., 5, 826-839, https://doi.org/ 10.1093/nsr/nwy105.

Taylor, K. E., R. J. Stouffer, and G. A. Meehl, 2012: An overview of CMIP5 and the experiment design. Bull. Amer. Meteor. Soc., 93, 485-498, https://doi.org/10.1175/BAMS-D-11-00094.1.

Thayer-Calder, K., and D. Randall, 2015: A numerical investigation of boundary layer quasi-equilibrium. Geophys. Res. Lett., 42, 550-556, https://doi.org/10.1002/2014GL062649.

Tulich, S. N., and B. E. Mapes, 2010: Transient environmental sensitivities of explicitly simulated tropical convection. J. Atmos. Sci., 67, 923-940, https://doi.org/10.1175/2009JAS3277.1.

Wang, S., A. H. Sobel, and J. Nie, 2016: Modeling the MJO in a cloud-resolving model with parameterized large-scale dynamics: Vertical structure, radiation, and horizontal advection of dry air. J. Adv. Model. Earth Syst., 8, 121139, https://doi.org/10.1002/2015MS000529.

Wolding, B. O., and E. D. Maloney, 2015: Objective diagnostics and the Madden-Julian oscillation. Part II: Application to moist static energy and moisture budgets. J. Climate, 28, 77867808, https://doi.org/10.1175/JCLI-D-14-00689.1.

,-- , and M. Branson, 2016: Vertically resolved weak temperature gradient analysis of the Madden-Julian oscillation in SP-CESM. J. Adv. Model. Earth Syst., 8, 1586-1619, https:// doi.org/10.1002/2016MS000724.

— J. Jias, G. Kiladis, F. Ahmed, S. W. Powell, E. Maloney, and M. Branson, 2020: Interactions between moisture and tropical convection. Part I: The coevolution of moisture and convection. J. Atmos. Sci., 77, 1783-1799, https://doi.org/10.1175/JAS-D-190225.1.

Xu, W., and S. A. Rutledge, 2014: Convective characteristics of the Madden-Julian oscillation over the central Indian Ocean observed by shipborne radar during DYNAMO. J. Atmos. Sci., 71, 2859-2877, https://doi.org/10.1175/JAS-D-13-0372.1.

Yanai, M., S. Esbensen, and J. Chu, 1973: Determination of bulk properties of tropical cloud clusters from large-scale heat and moisture budgets. J. Atmos. Sci., 30, 611-627, https://doi.org/ 10.1175/1520-0469(1973)030<0611:DOBPOT >2.0.CO;2.

Yano, J.-I., and K. Emanuel, 1991: An improved model of the equatorial troposphere and its coupling with the stratosphere. J. Atmos. Sci., 48, 377-389, https://doi.org/10.1175/ 1520-0469(1991)048<0377:AIMOTE > 2.0.CO;2.

_ , and M. Bonazzola, 2009: Scale analysis for large-scale tropical atmospheric dynamics. J. Atmos. Sci., 66, 159-172, https:// doi.org/10.1175/2008JAS2687.1.

Yokoi, S., and A. H. Sobel, 2015: Intraseasonal variability and seasonal march of the moist static energy budget over the eastern maritime continent during CINDY2011/DYNAMO. J. Meteor. Soc. Japan, 93A, 81-100, https://doi.org/10.2151/ jmsj.2015-041.

Yoneyama, K., C. Zhang, and C. N. Long, 2013: Tracking pulses of the Madden-Julian oscillation. Bull. Amer. Meteor. Soc., 94, 1871-1891, https://doi.org/10.1175/BAMS-D-12-00157.1.

Yu, H., R. H. Johnson, P. E. Ciesielski, and H.-C. Kuo, 2018: Observation of quasi-2-day convective disturbances in the equatorial Indian Ocean during DYNAMO. J. Atmos. Sci., 75, 2867-2888, https://doi.org/10.1175/JAS-D-17-0351.1.

Zhang, G. J., and N. A. McFarlane, 1995: Role of convective scale momentum transport in climate simulation. J. Geophys. Res., 100, 1417-1426, https://doi.org/10.1029/94JD02519.

Zuluaga, M. D., and R. A. Houze, 2013: Evolution of the population of precipitating convective systems over the equatorial Indian Ocean in active phases of the Madden-Julian oscillation. J. Atmos. Sci., 70, 2713-2725, https://doi.org/10.1175/ JAS-D-12-0311.1. 